\title{
Multi-scale hydrometeorological observation and modelling for flash flood understanding
}

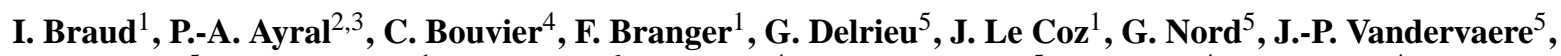 \\ S. Anquetin ${ }^{5}$, M. Adamovic ${ }^{1}$, J. Andrieu ${ }^{6}$, C. Batiot ${ }^{4}$, B. Boudevillain ${ }^{5}$, P. Brunet ${ }^{4}$, J. Carreau ${ }^{4}$, A. Confoland ${ }^{5}$, \\ J.-F. Didon-Lescot ${ }^{3}$, J.-M. Domergue ${ }^{3}$, J. Douvinet ${ }^{7}$, G. Dramais ${ }^{1}$, R. Freydier ${ }^{4}$, S. Gérard ${ }^{5}$, J. Huza ${ }^{1,8}$, E. Leblois ${ }^{1}$, \\ O. Le Bourgeois ${ }^{4}$, R. Le Boursicaud ${ }^{1}$, P. Marchand ${ }^{4}$, P. Martin ${ }^{7}$, L. Nottale ${ }^{9}$, N. Patris ${ }^{4}$, B. Renard ${ }^{1}$, J.-L. Seidel ${ }^{4}$, \\ J.-D. Taupin ${ }^{4}$, O. Vannier ${ }^{5}$, B. Vincendon ${ }^{10}$, and A. Wijbrans ${ }^{5}$ \\ ${ }^{1}$ Irstea, UR HHLY, Hydrology-Hydraulics, Villeurbanne, France \\ ${ }^{2}$ Ecole des Mines d'Alès, Alès, France \\ ${ }^{3}$ ESPACE, UMR 7300 CNRS, “Antenne Cevenole”, Université de Nice-Sophia-Antipolis, \\ Université d'Avignon et des Pays de Vaucluse, France \\ ${ }^{4}$ Hydrosciences, UMR 5569 CNRS, IRD, Université de Montpellier II, Montpellier, France \\ ${ }^{5}$ LTHE, UMR 5564 CNRS, IRD, Université de Grenoble, Grenoble, France \\ ${ }^{6}$ ESPACE, UMR 7300 CNRS, Université de Nice, Nice, France \\ ${ }^{7}$ ESPACE, UMR 7300 CNRS, Université d'Avignon et du Pays de Vaucluse, Avignon, France \\ ${ }^{8}$ Centre for Water and Climate, Wageningen University, Wageningen, the Netherlands \\ ${ }^{9}$ Observatoire de Paris-Meudon, CNRS LUTH et Université de Paris Diderot, Meudon, France \\ ${ }^{10}$ CNRM-GAME, UMR 3589, Météo-France et CNRS, Toulouse, France
}

Correspondence to: I. Braud (isabelle.braud@irstea.fr)

Received: 17 December 2013 - Published in Hydrol. Earth Syst. Sci. Discuss.: 11 February 2014

Revised: 6 June 2014 - Accepted: 25 June 2014 - Published: 26 September 2014

\begin{abstract}
This paper presents a coupled observation and modelling strategy aiming at improving the understanding of processes triggering flash floods. This strategy is illustrated for the Mediterranean area using two French catchments (Gard and Ardèche) larger than $2000 \mathrm{~km}^{2}$. The approach is based on the monitoring of nested spatial scales: (1) the hillslope scale, where processes influencing the runoff generation and its concentration can be tackled; (2) the small to medium catchment scale $\left(1-100 \mathrm{~km}^{2}\right)$, where the impact of the network structure and of the spatial variability of rainfall, landscape and initial soil moisture can be quantified; (3) the larger scale $\left(100-1000 \mathrm{~km}^{2}\right)$, where the river routing and flooding processes become important. These observations are part of the HyMeX (HYdrological cycle in the Mediterranean EXperiment) enhanced observation period (EOP), which will last 4 years (2012-2015). In terms of hydrological modelling, the objective is to set up regional-scale models, while addressing small and generally ungauged catchments, which represent the scale of interest for flood risk assessment. Top-
\end{abstract}

down and bottom-up approaches are combined and the models are used as "hypothesis testing" tools by coupling model development with data analyses in order to incrementally evaluate the validity of model hypotheses. The paper first presents the rationale behind the experimental set-up and the instrumentation itself. Second, we discuss the associated modelling strategy. Results illustrate the potential of the approach in advancing our understanding of flash flood processes on various scales.

\section{Introduction}

The Mediterranean area is prone to intense rainfall events, sometimes triggering flash floods that may have dramatic consequences (e.g. Ruin et al., 2008). Although several studies have addressed flash floods, understanding the processes leading to them is still an active research question. Before any further analysis, it is necessary to define what a flash 
flood is. Gaume et al. (2004) cite an IAHS-UNESCO-WMO (1974) definition of flash floods: "sudden floods with high peak discharges, produced by severe thunderstorms that are generally of limited areal extent", which is quite vague. In a further study compiling flash flood data across Europe, Gaume et al. (2009) write “...extreme flood events induced by severe stationary storms have been considered as flash floods...". They underline that flash floods are generally associated with intense rainfall exceeding $100 \mathrm{~mm}$ in a few hours and affecting limiting areas (see also Douvinet and Delahaye, 2010). Nevertheless, they also point out that the generating rainfall can also be long-lasting rainfall (about $24 \mathrm{~h}$ with moderate intensities but leading to accumulative rainfall of several hundreds of millimetres), which is quite specific to the Mediterranean region (e.g. Delrieu et al., 2005). In terms of magnitude, Gaume et al. (2009) show that their European flash floods sample was characterized by specific peak discharges ranging from about 0.5 to $40 \mathrm{~m}^{3} \mathrm{~s}^{-1} \mathrm{~km}^{-2}$. In the following, we retain the following criteria for the definition of a flash flood. The rise of the hydrographs should be very short (a few hours or less for catchments of $1-100 \mathrm{~km}^{2}$ and less than $24 \mathrm{~h}$ for catchments of about $1000 \mathrm{~km}^{2}$ ). To be considered as flash floods, the events must also have a significant peak discharge, larger than $0.5 \mathrm{~m}^{3} \mathrm{~s}^{-1} \mathrm{~km}^{-2}$.

Such flash flood events are characterized by time- and space scales that conventional measurement networks are not always able to sample (Creutin and Borga, 2003; Kirchner, 2006). In addition, flash floods are locally rare events, so they are difficult to capture by field-based experiments (Borga et al., 2008). Borga et al. (2008) recommend the use of eventbased and opportunistic observations, in particular post-flood surveys, to try to understand the processes leading to flash floods. A standardized method for post-flood field surveys was proposed by Gaume and Borga (2008) and Marchi et al. (2009). During the HYDRATE EU project (Borga et al., 2011), a significant effort was dedicated to the collection of hydrometeorological data on flash floods in Europe (Gaume et al., 2009; Marchi et al., 2010), leading to new insights into flash flood characteristics (Borga et al., 2011). Spatial and temporal rainfall variability, landscape characteristics and soil humidity are recognized as important influential factors in flash flood generation (Borga et al., 2010). Several authors (Sangati et al., 2009; Anquetin et al., 2010; Viglione et al., $2010 \mathrm{a}, \mathrm{b})$ proposed methods to determine the characteristic spatial and temporal scales of the processes leading to flash floods. Borga et al. (2008) and Bouilloud et al. (2010) showed that it is essential to use high-resolution space-time rainfall fields provided by weather radars to properly analyse and understand flash floods. Others showed the importance of topography (Norbiato et al., 2009), geology, soils (Anquetin et al., 2010; Braud et al., 2010; Martin, 2010) and initial soil moisture (Borga et al., 2007; Le Lay and Saulnier, 2007; Gaume et al., 2009; Tramblay et al., 2010) or the impact of hydraulic routing within the river network and geomorphological controls (Bonnifait et al., 2009). Depending on the conditions, one or several factors can impact the hydrological response significantly. As a consequence, the predictability of such events remains low. In addition, this predictability is lowered by a high non-linearity in the hydrological response related to threshold effects (Rogger et al., 2012) and structured heterogeneity on all scales (Blöschl and Zehe, 2005).

Thus, assessing flash flood susceptibility and understanding flash flood processes further require a multi-scale and cross-combined hydrometeorological approach. Furthermore, it is necessary to transfer the knowledge acquired on a given scale to another scale, the so-called change-of-scale problem (Blöschl and Sivapalan, 1995; Sivapalan, 2003a). Additionally, to assess the risk everywhere, it is necessary to provide reliable hydrological simulations and predictions in ungauged basins (the PUB problem, see Sivapalan, 2003a; Hrachowitz et al., 2013) and on various scales (from a few $\mathrm{km}^{2}$ to $1000 \mathrm{~km}^{2}$ ). Kirchner (2006) advocates field experiments specifically designed to address the change-of-scale problem in order "to get the right answer for the right reasons" (Klemes, 1986; Grayson et al., 1992). The strategy is based on nested catchments, allowing the sampling of spatial heterogeneity on all scales (Sivapalan, 2003b). Examples of the use of this strategy are the CUASHI initiative (Reed et al., 2006) and the AMMA project (Lebel et al., 2009).

This study builds on these recommendations and is focused on the monitoring, understanding and modelling of flash floods in the Mediterranean context. It contributes to the enhanced observation period of the HyMeX (HYdrological cycle in Mediterranean Experiment) program (Drobinski et al., 2014), the FloodScale project (http://floodscale.irstea. $\mathrm{fr} /$ ) and the Cévennes-Vivarais Mediterranean Hydrometeorological Observatory (OHM-CV, http://www.ohmcv.fr, Boudevillain et al., 2011). The two main scientific questions we are addressing are as follows:

1. How can we document the variability from the hillslope scale to the regional scale of active hydrological processes between and during flash floods?

2. How can we describe and simulate the corresponding processes on the various scales?

To address these questions, the study relies on the collection of new data on flash flood and hydrological processes on all scales and their corresponding hydrological modelling. The experimental set-up relies on multi-scale (nested sub-catchments) field-based observations, covering the regional scale (two catchments of about $2000 \mathrm{~km}^{2}$ ), complemented with opportunistic measurements during high, intense rainfall events affecting those catchments. The opportunistic measurements are conducted during special observation periods (SOPs) in autumn, in particular during HyMeX SOP1 conducted in autumn 2012 (Ducrocq et al., 2014). The nested sub-catchments are representative of the variability of landscape conditions in the Mediterranean region. 
The multi-scale approach allows the documentation of active, small-scale processes and of how they aggregate on larger scales (Fig. 1). The length of the experiment and the setting of continuous measurements allow the documentation of "normal" catchment behaviour as well as "extreme" behaviour in order to capture potential threshold effects and/or abrupt changes in catchment functioning. From our experience (see Braud et al., 2014a), the 4-year duration of the experiment and the large area involved in the monitoring, ensures that significant events will be captured within the duration of the monitoring in at least one of the small catchments. Long-term time series from operational networks are also collected and analysed to get information about hydrological processes over longer timescales. Finally, an innovative monitoring strategy for flash floods, relying on recent progress in instrumentation and sensors, is proposed, complemented by opportunistic measurements to document discharges and soil moisture conditions during floods, as well as to perform geochemistry sampling to trace back water origin. Data analysis and models are combined in an iterative way (Fig. 2) to increase our process understanding and modelling capability. In the particular case of flash floods, the collection of new data is of paramount importance as flash floods are expected to trigger previously unobserved behaviours (Borga et al., 2008).

This paper presents the multi-scale observation strategy for two large Mediterranean catchments in France (Sect. 2) and the associated modelling approach (Sect. 3). Then the potential of this strategy is illustrated first using data analysis and modelling results (Sect. 4) before drawing conclusions and discussing perspectives (Sect. 5).

\section{The multi-scale observation set-up}

\subsection{Introduction}

The experimental set-up focuses on two pilot sites in France: the Gard and the Ardèche catchments (Fig. 3), which belong to the OHM-CV network.

The observation strategy relies on nested-catchments instrumentation (mostly continuous over the 4-year duration of the experiment) covering the following spatial scales (Fig. 1):

1. the hillslope scale, where processes influencing runoff generation and its concentration can be tackled;

2. the small- to medium-catchment scale $\left(1-100 \mathrm{~km}^{2}\right)$ where the impact of network structure and of the spatial variability of rainfall, landscape and initial soil moisture can be quantified;

3. the larger scale $\left(100-1000 \mathrm{~km}^{2}\right)$, where the river routing and flooding processes become important.

Innovative observations (enhanced weather radar, disdrometer networks, stream gauging using non-contact techniques, dense limnimeter networks, very high resolution

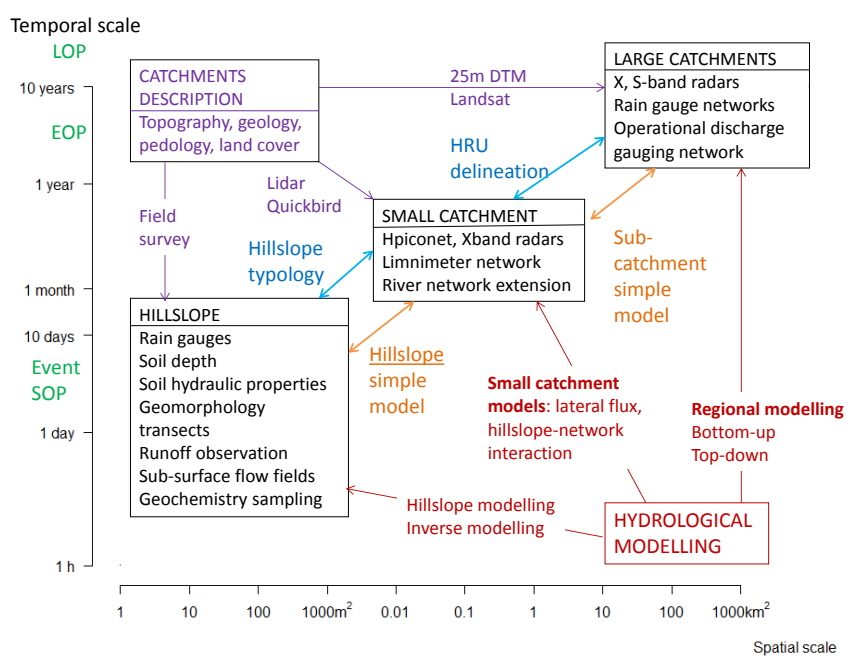

Figure 1. Diagram showing the characteristic spatial scales of the processes considered in the study (black boxes, diagonal from bottom left to top right) and the associated typical observation timescales; the required data characterizing the catchments physical properties for each scale (purple box, top left); the modelling approaches (red box, bottom right). Interactions between scales and the question of how the change-of-scale problem is addressed are shown with the blue arrows for the model meshing and orange arrows for the process representation. HRU means hydrological response unit.

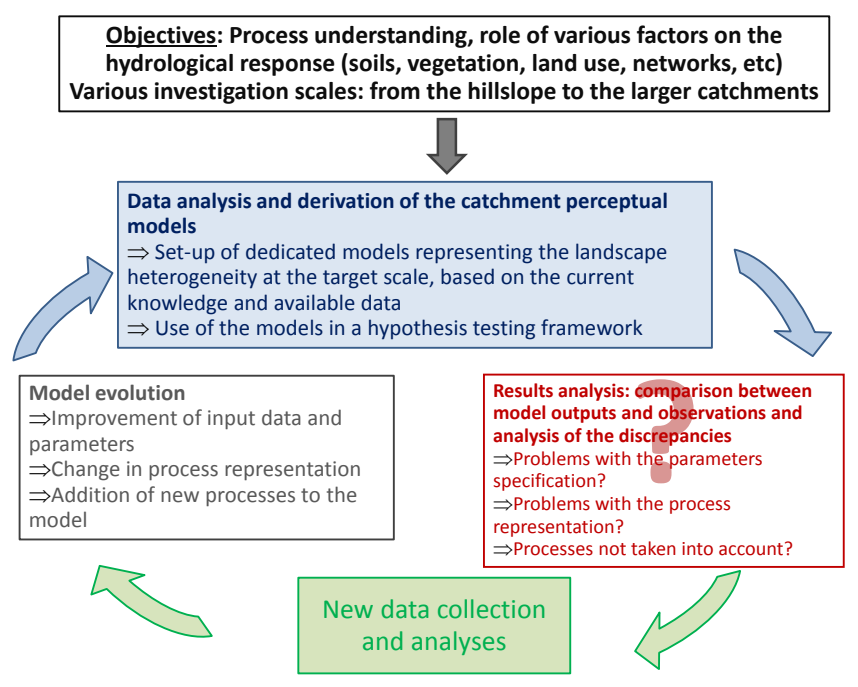

Figure 2. Proposed iterative approach combining observation and modelling to advance our understanding of the processes and their modelling.

remote-sensing data, lidar digital elevation models (DEMs), etc.) complement the traditional measurements (rain gauges, water level, soil moisture, etc). The set-up also favours the combination of various measurements on the same hillslopes/catchments in order to enhance the potential for understanding the active processes during and between floods. 


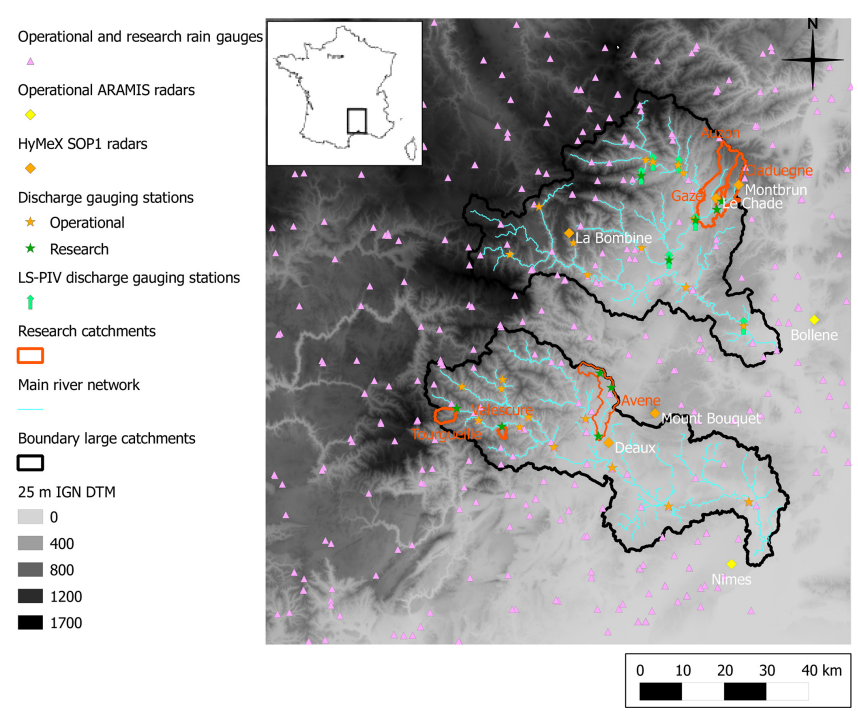

Figure 3. Location and elevation map of the study area. The two main catchments studied: Gard $\left(2062 \mathrm{~km}^{2}\right)$ and Ardèche $\left(2388 \mathrm{~km}^{2}\right)$, are outlined by the bold black line. The small research catchments are shown with orange boundaries. The figure also shows the operational rain gauge network, the operational and research meteorological radar network, as well as the operational and research (standard and LS-PIV) discharge gauging stations.

This site-based strategy is complemented with opportunistic measurements during floods. When trying to capture flash flood events in a given region, and especially in the three small catchments, it is important to have an idea of the likelihood of observing above-threshold events during the 4-year duration of the experiment. The discharge time series at our disposal are not long enough to perform the same kind of study as the one proposed by Troutman and Karlinger (2003). However, it is possible to use long series (1951-2003) of daily precipitation from three rain gauges located close to the three small catchments as a proxy for this assessment. We have computed the frequency with which large precipitation events have been recorded by these three rain gauges, and the probability of recording a value higher than $150 \mathrm{~mm}$ is $\approx 0.4$ and decreases to $\approx 0.2$ for $200 \mathrm{~mm}$ (see details in Braud et al., 2014b). However, over the 4-year project duration, these probabilities increase to $\approx 0.9$ and $\approx 0.5$ respectively. The likelihood of recording precipitation values above $150 \mathrm{~mm}$ is therefore quite high over the project duration, which gives hope that flood events will also be monitored on the three small catchments.

In the following, we successively describe, for the various scales, the scientific questions addressed by the experiments (see also Fig. 1) and the experimental set-up itself. Opportunistic data collection during floods is also described.

\subsection{Experimental set-up on the hillslope scale}

Hillslope is recognized as the appropriate scale to assess flow-generating processes. Recent papers show that, in a context with sub-surface dominant flow, the long-term monitoring of various hillslopes can lead to the emergence of new concepts such as the "fill and spill" mechanisms, underlying the role of bedrock micro-topography on runoff initiation, connection and propagation (Tromp-van Meerveld and McDonnell, 2006; Anderson et al., 2009; Graham et al., 2010). Based on such a perceptual model, modelling studies using 3 -D models and virtual experiments (Weiler and McDonnell, 2004; Herbst et al., 2006; Fiori et al., 2007; Hopp and McDonnell, 2009; James et al., 2010) were used to assess the major control on the hillslope response (slope, bedrock permeability, soil depth, rainfall depth) or to derive new modelling approaches (e.g. Lehmann et al. (2007) based on percolation theory). The "fill and spill" concept and the associated sub-surface flow was found to apply in other locations in the world (Uchida et al., 2005) and could be relevant for part of the Cévennes-Vivarais region, which is our region of interest (Cosandey and Didon-Lescot, 1990; Tramblay et al., 2010), especially in the forested area and granite lithology. In this region, infiltration and runoff field experiments (Ayral, 2005; Marchandise, 2007) showed that the infiltration capacity of the topsoil was very high (a few hundreds of millimetres per hour) in the forested and granite lithology, generally excluding surface runoff as an active mechanism. These experiments and modelling studies (Anquetin et al., 2010; Braud et al., 2010) also raise questions about the imperviousness of the bedrock, which is often assumed in models. For schist lithology, on the field scale, Brunet et al. (2010) also show the existence of soil saturation at the interface between the soil and the bedrock, but only ephemerally at the soil surface (Le Bourgeois et al., 2012). Other studies conducted in cultivated areas (mainly vineyards) showed that surface Hortonian runoff may also be a dominant mechanism in the study region (Hébrard et al., 2006; Nicolas, 2010). Runoff studies based on rainfall simulations and the analysis of in situ events showed that a process similar to the "fill and spill" mechanism mentioned above can be encountered at the soil surface, in relation to micro-topography and vegetation (Nicolas, 2010). Of course, during an event, and according to the rainfall intensity or soil saturation, the dominant process can change. When rainfall intensities become very high, surface runoff can be observed even in areas classified as "prone to sub-surface runoff". Rocks are sometimes encountered at the surface, which leads to surface runoff whatever the rainfall intensity.

In the present study, the experimental set-up aims at characterizing the dominant processes during and between floods for different types of Mediterranean hillslopes, the final objective being the definition of a hillslope typology, allowing a spatialization of the results to non-monitored catchments. For this purpose, various hillslopes typical of the Mediterranean 
Table 1. Hillslope experimental set-up.

\begin{tabular}{|c|c|c|c|}
\hline Instrumented slopes & Valescure (Gard) & Tourgueille (Gard) & Pradel/Gazel (Ardèche) \\
\hline Slope characteristics & $\begin{array}{l}\text { Steep slopes, } \\
\text { natural vegetation, } \\
\text { granite bedrock }\end{array}$ & $\begin{array}{l}\text { Steep slopes, } \\
\text { natural vegetation, } \\
\text { schist bedrock }\end{array}$ & $\begin{array}{l}\text { Moderate slopes, } \\
\text { cultivated area (vineyard, pasture), } \\
\text { sedimentary clay limestone bedrock }\end{array}$ \\
\hline $\begin{array}{l}\text { Dominant processes } \\
\text { expected }\end{array}$ & $\begin{array}{l}\text { Saturation-excess runoff, } \\
\text { sub-surface flow }\end{array}$ & $\begin{array}{l}\text { Saturation-excess runoff, } \\
\text { sub-surface flow }\end{array}$ & $\begin{array}{l}\text { Surface flow on cultivated areas, } \\
\text { unknown in pastures or forests }\end{array}$ \\
\hline $\begin{array}{l}\text { Surface runoff } \\
\text { measurements }\end{array}$ & None & None & $\begin{array}{l}\text { One vineyard hillslope studied in } \\
\text { Nicolas (2010); several fields tested } \\
\text { with new prototype of rainfall simulator }\end{array}$ \\
\hline $\begin{array}{l}\text { Soil moisture } \\
\text { measurements }\end{array}$ & $\begin{array}{l}20 \text { soil moisture sensors } \\
(10 \text { points and } 2 \text { depths } \\
-20,40 \mathrm{~cm}) \text { during } 1 \text { year } \\
\text { on } 3 \text { hillslope transects }\end{array}$ & $\begin{array}{l}\text { Same as Valescure } \\
\text { on } 1 \text { hillslope transect }\end{array}$ & $\begin{array}{l}\text { Continuous soil moisture at } 10(2), \\
20-25(2) \text { and } 30-40(1) \mathrm{cm} \\
\text { in two vineyards, one piece of fallow land, } \\
\text { four pastures, two forests since May } 2013\end{array}$ \\
\hline $\begin{array}{l}\text { Sub-surface } \\
\text { flow measurements }\end{array}$ & $\begin{array}{l}2 \text { different fields with natural } \\
\text { and artificial events }\end{array}$ & None & None \\
\hline Soil topography & 1 m lidar DEM & $1 \mathrm{~m}$ lidar DEM & 1 m lidar DEM \\
\hline Soil hydraulic properties & Infiltrometers & Infiltrometers & Infiltrometers, Beerkan tests \\
\hline $\begin{array}{l}\text { Soil depth and bedrock } \\
\text { topography }\end{array}$ & Perforation method & Perforation method & Perforation method \\
\hline Geophysical survey & Electrical resistivity & If possible & Not scheduled yet \\
\hline $\begin{array}{l}\text { Landscape segments } \\
\text { analysis (pedology) }\end{array}$ & In detail with field work & $\begin{array}{l}\text { General field survey } \\
\text { and GIS* analysis }\end{array}$ & $\begin{array}{l}\text { General field survey } \\
\text { and GIS analysis }\end{array}$ \\
\hline Vegetation analysis & $\begin{array}{l}\text { In detail with field work } \\
\text { and VHR image analysis }\end{array}$ & $\begin{array}{l}\text { Only general survey } \\
\text { and VHR image analysis }\end{array}$ & $\begin{array}{l}\text { Only general survey } \\
\text { and VHR image analysis }\end{array}$ \\
\hline
\end{tabular}

* geographical information system.

environment in terms of spatial variability in soil depth, soil hydraulic properties, pedology, vegetation and geomorphology are selected and instrumented. We also explore the permeability/imperviousness and storage capacity of the underlying altered bedrock. Soil moisture variations and the impact of topography and vegetation on pre-event initial soil moisture are also documented. The instrumented hillslopes are located in three small catchments (Valescure, Tourgueille, Gazel), corresponding to different geologies (Table 1 and Fig. 3). Details on instrumentation and protocols are provided below and summarized in Table 1.

\subsubsection{Hillslope monitoring}

In the Gard catchments, with granite or schist lithology and a forest land cover, saturation excess is thought to be dominant (see above). For this type of dominant runoff process, the experimental set-up is the following. Several hillslopes are selected according to lithology, slope, aspect, vegetation and a transect from the bottom to the top of the slope is instrumented. In each transect, soil water content is measured continuously at 10 locations and 2 depths $(20 \mathrm{~cm}$ and the closest to the altered bedrock) to document the initial water deficit at the beginning of a rain event. In addition, the long-term variation of soil water content is of interest in order to assess topography and vegetation influence on soil moisture redistribution, as well as to document potential soil saturation. The sensors are left in place for 1 year to monitor the whole hydrological cycle, then dismantled and moved to another hillslope. The chosen duration relies on the hypothesis that one hydrological year is enough to sample both dry and humid conditions and determine the response time of soil moisture as well as the associated soil hydraulic properties. Four transects have already been instrumented in the Valescure catchment ${ }^{1}$ (Figs. 3 and 4a) with different lithologies (granite, orthogneiss), aspects (east or west) and slopes (20$40^{\circ}$ ). The fifth transect has just been installed in the Tourgueille catchment (Figs. 3 and $4 \mathrm{~b}$ ) on schist lithology.

When the transect is dismantled, a geomorphology and vegetation survey is performed along the transect using the "landscape segments" method (Filleron, 1995; Morschel,

\footnotetext{
${ }^{1}$ http://mistrals.sedoo.fr/HyMeX/Parameter-search/ ?editDatsId $=878 \&$ datsId $=878 \&$ project_name $=$ HyMeX
} 


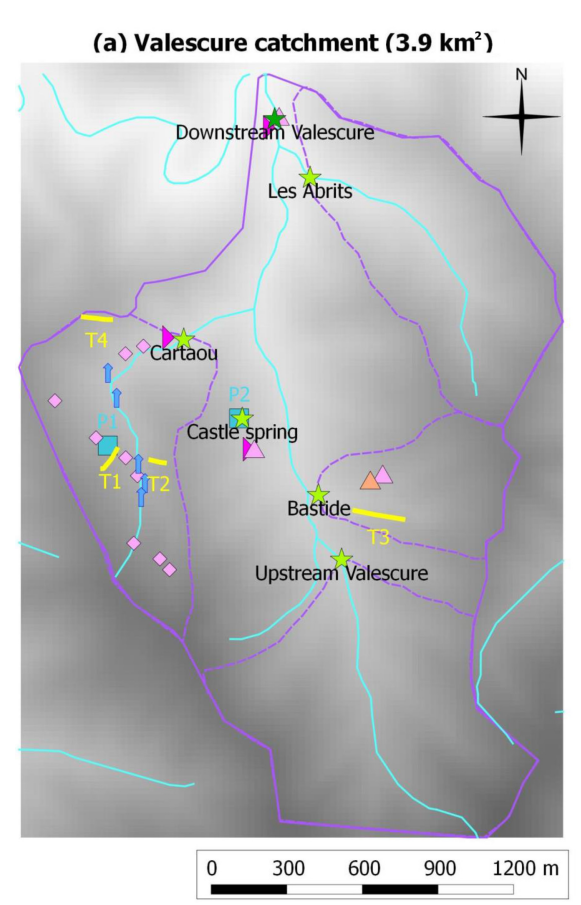

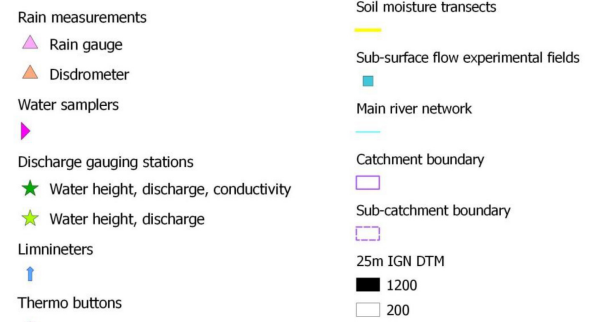

(b) Tourgueille catchment $\left(10 \mathrm{~km}^{2}\right)$

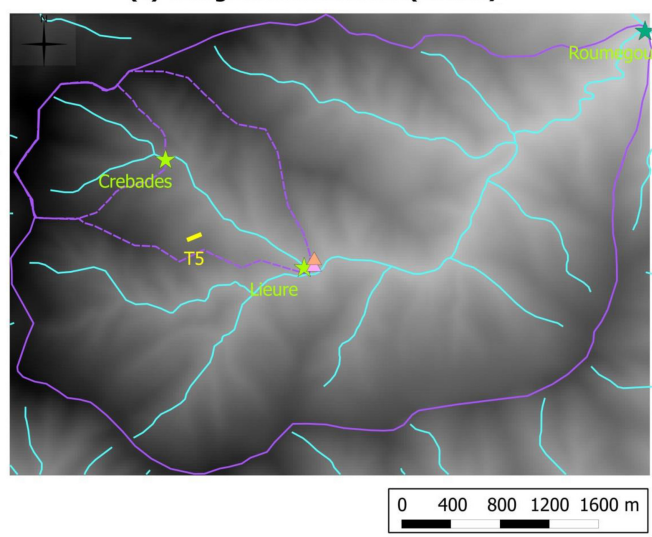

Figure 4. Elevation map and instrumentation of (a) the Valescure catchment $\left(3.9 \mathrm{~km}^{2}\right)$; (b) the Tourgueille catchment $(10 \mathrm{~km})^{2}$ in the Gard catchment.

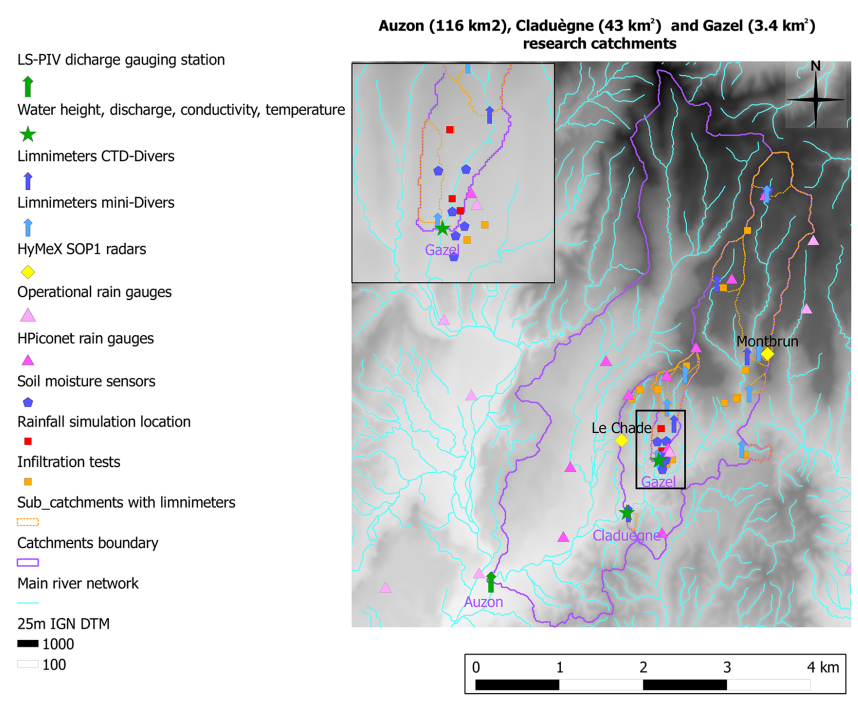

Figure 5. Elevation map and instrumentation of the Gazel $\left(3 \mathrm{~km}^{2}\right)$, Claduègne $\left(43 \mathrm{~km}^{2}\right)$ and Auzon $\left(116 \mathrm{~km}^{2}\right)$ catchments in the Ardèche catchment. The black rectangle shows the position of the zoom provided at the top left of the figure.

2006) to document the landscape organization and its geomorphological dynamics, in particular water pathways. This method requires intensive field work (pedology pits, vegetation structure identification). A multidimensional, quantitative and spatialized description of the vegetation (Lecompte,
1973) is used with a separate observation of horizontal structure, vegetation ground cover and vertical structure (in relation to interception). In addition, the main soil properties are characterized along each transect, in order to assess mean values and spatial variability. Particle size analysis, dry bulk density measurements and infiltrometry (Vandervaere et al., $2000)$ provide the textural and hydraulic soil properties. Electrical resistivity (Brunet et al., 2010) combined with mechanical perforations is used to characterize the soil depth.

In the Gazel catchment (Ardèche catchment; see location in Fig. 3), where infiltration excess runoff is thought to be the dominant process (e.g. Nicolas, 2010), the experiments focus on the documentation of the soil infiltration capacity and initiation of ponded conditions at the surface. First, nine sites (see location in Fig. 5) with different land uses (two vineyards, four pastures, one piece of fallow land, two small oak woods) are selected. They have been equipped since April 2013 with continuous soil moisture measurements at about 10,20 and $30-50 \mathrm{~cm}$ depth, in order to document soil saturation. Second, specific field campaigns are conducted to document the spatially distributed soil response times to rainfall: between rainfall onset and soil surface saturation (signature of soil surface properties and initial moisture condition), and between soil surface saturation and runoff (signature of surface micro-topography). The idea is to find a way to rank various land uses in terms of infiltration capacity and runoff generation while avoiding long time-consuming infiltration tests based on infiltrometers. For this purpose, 
a simplified rainfall simulator, called a "saturometer", is proposed. As compared to previous rainfall simulator types, the water quantity needed to feed the apparatus is reduced and it can be fed with a manual pump. The size of the wetted surface is about $1 \mathrm{~m}^{2}$ and the rainfall intensity can range from 5 to $250 \mathrm{~mm} \mathrm{~h}^{-1}$. Instead of waiting for the permanent regime, the time of ponding is determined visually. An analytical relationship between ponding time and rainfall intensity is used to derive estimates of hydraulic conductivity and capillary sorptivity, according to equations proposed by Boulier et al. (1987). The saturometer was tested in 2013 in three fields (see location in Fig. 5) (two vineyards and one pasture). It will be moved to other fields in the coming years to sample additional land uses. More details about the saturometer can be found in Vandervaere et al. (2014) and Malam (2014). To complement the analysis, fields are monitored for runoff and erosion using devices described in Nicolas (2010) and Grangeon (2012).

\subsubsection{Characterization of sub-surface flow and bedrock role}

In the Gard catchment, an important issue is also to determine the role of sub-surface runoff in flood generation, either by direct contribution to the flood volumes or by drainage of the soils during inter-events, as well as the role of bedrock. The experimental set-up combines various measurements (Buttle and McDonald, 2002; Joerin et al., 2005; Trompvan Meerveld et al., 2007; Kientzler and Naef, 2008; Graham et al., 2010; Burke and Kasahara, 2011): soil moisture probes, piezometers, trench for sub-surface flow collecting, sprinklers or upslope trench for water input and natural or chemical tracers (see Fig. 6). One $10 \mathrm{~m}^{2}$ plot (P1) was implemented in spring 2012 (see location in Fig. 4a) and was dismantled in 2013 after recording four artificial rainfall events and 20 natural ones. This first plot is characterized by a steep slope (about $40^{\circ}$ ) and relatively deep soils (about $80 \mathrm{~cm}$ ). The second one (P2) was installed in October 2013 in shallower soils (about $50 \mathrm{~cm}$ ) and on a lower slope $\left(20^{\circ}\right)$ (Fig. 4a). The protocol was incrementally improved during the first events and is now stabilized as follows. Two rainfall configurations can be applied: a homogeneous rainfall on the plot or a rainfall only at the top of the slope -in either case with a constant intensity. Three piezometers are inserted into the soil and are open only at the bottom to document possible saturation at the soil-bedrock interface. Close to the piezometers, two soil moisture probes and two tensiometers are installed at various depths as indicated in Fig. 6. Electrodes for the monitoring of electrical resistivity during the rainfall event are also installed close to the piezometers. Finally, salt can be injected in a trench at the top of the slope and the electrical conductivity is monitored in the piezometers and/or thanks to electrical resistivity.

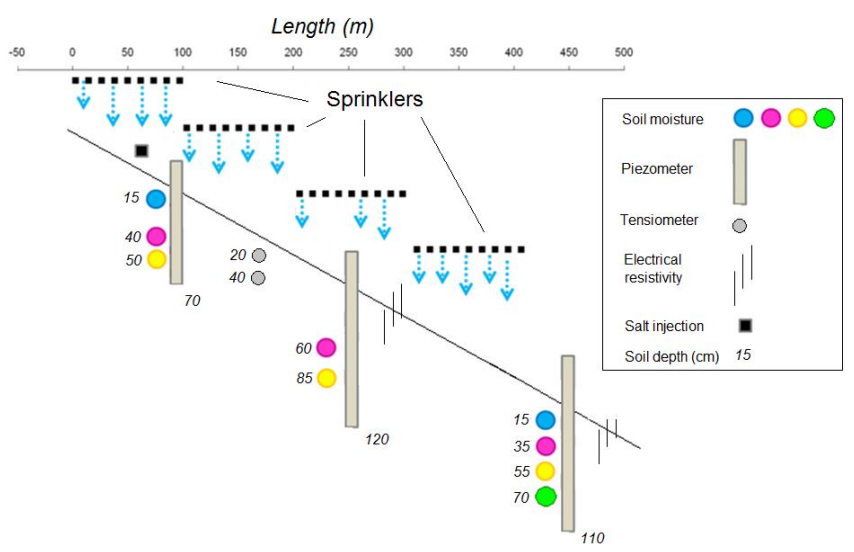

Figure 6. Scheme of the experimental set-up in the $10 \mathrm{~m}^{2}$ plot for sub-surface flow and bedrock permeability study based on artificial and natural rainfall events. The device combines soil moisture probes, piezometers, tensiometers, electrodes for electrical resistivity and salt injection in order to characterize both vertical and lateral flows in the soil.

\subsubsection{Data analysis and generalization}

To analyse water content time series from the transects, inverse modelling based on the Richards equation is performed in order to retrieve the intrinsic soil properties following methods derived from Loew and Mauser (2008) and Wollschläger et al. (2009) (see Le Bourgeois et al., 2012). The results are summarized in terms of spatial statistical distribution of soil characteristics for a given hillslope. These distributions are compared amongst hillslopes. Relationships between the statistical distributions of the hillslope properties and the general features of the landscape such as slope, geomorphology and vegetation are studied (e.g. Ali et al., 2012a). These landscape features are used to provide a hillslope typology, based on the processing of very high resolution images acquired in the small catchments: $1 \mathrm{~m}$ resolution DEM (lidar data) and $0.5 \mathrm{~m}$ resolution satellite images (Quickbird and/or Pléiades images), leading to a hillslope typology relating soil moisture dynamics, infiltration capacity, soil hydraulic properties, soil structure and vegetation to more easily measurable quantities (Morschel, 2011). The sub-surface flow field experiments, as well as the electrical resistivity surveys, are analysed to understand water pathways within the topsoil and the underlying altered bedrock in order to derive lateral flow velocity and test the relevance of the "fill and spill" mechanism. If possible, the altered bedrock storage capacity will be assessed. All the data acquired on the hillslope scale can be used to run detailed models of hillslopes with different hypotheses about active processes (e.g. Troch et al., 2003; Weiler and McDonnell, 2004, 2007; Graham and McDonnell, 2010) in order to verify the consistency between the observed and simulated water pathways and fluxes. 


\subsection{Experimental set-up on the small catchment scale}

On the small catchment scale, runoff coefficients are generally shown to decrease with increasing catchment size (e.g. Braud et al., 2001; Cerdan et al., 2004). In recent years, as for hillslope (e.g. Hopp and McDonnell, 2009), the concept of hydrologic connectivity has emerged as a unifying framework for understanding the catchment behaviour on different scales further (e.g. Ambroise, 2004; Bracken and Croke, 2007; Lexartza-Artza and Wainwright, 2009). These papers distinguish the structural connectivity (which is static) from the functional connectivity which focuses on the role of various objects in the landscape (e.g. ponds, buffer, change in slopes) in producing runoff, storing water or transferring it (Sivapalan, 2003b). Recent work has shown that dense limnimeter networks combined with very-high-resolution lidar DEM provide valuable insight into the connectivity question for headwater catchments (Maréchal, 2011; Maréchal et al., 2012; Sarrazin, 2012). Various types of reaches can be identified. These can be artificialized reaches (such as ditches and roads) or natural reaches, either unchannelled or wellchannelled. Each type of reach has a different impact on flow continuity and velocity. The interpretation of such limnimeters networks also requires a high spatial and temporal resolution of rainfall fields for a correct interpretation of the hydrological response (e.g. Sarrazin, 2012).

The objectives of the experimental set-up in small to medium catchments $\left(1-100 \mathrm{~km}^{2}\right)$ are the following:

1. to document, in small catchments, the transition between hillslopes and network and the role of gullies in order to understand when and where runoff is produced and becomes concentrated;

2. to assess the effect of spatial and temporal variability of rainfall on the distributed hydrological responses in small to medium catchments $\left(1-100 \mathrm{~km}^{2}\right)$;

3. to compare effects of the intrinsic properties of the subcatchments (soil properties, land use, geology, etc.), the initial condition (soil moisture) and the spatial and temporal variability of rainfall on the rainfall-runoff relationships on different scales from the hillslope to the medium catchment;

4. to identify the hydrologically dominant processes in different medium catchments representative of the landscapes of the Mediterranean region and their characteristic hydrological "signatures" (e.g. Gupta et al., 2008);

5. to provide a map of "hydrological functioning units", also called "hydro-landscapes" (Dehotin and Braud, 2008) or "morphological functioning areas" (Douvinet et al., 2013), combining field observation, highresolution GIS layers, lidar DEM and the hillslope typology mentioned earlier.
In order to obtain high-resolution rainfall, relevant for the interpretation of the hydrological response to flash floods on a small scale (e.g. Creutin and Borga, 2003), research radars were deployed during the autumn in 2012 and 2013 (and will hopefully be deployed in the autumn of 2014) (see Ducrocq et al. (2014) for details), in combination with high-resolution rain gauge networks such as the HPiconet (see Fig. 5).

The data will be used to set up and assess distributed hydrological models, focusing mainly on lateral flow representation and network connection (see Sect. 3.2). The models will be used in a hypothesis testing framework (Clark et al., 2011; Fenicia et al., 2011) in an iterative way as shown in Fig. 2, allowing a better understanding of active processes, in particular an assessment of the relative importance of rainfall and landscape spatial variability. Table 2 presents a synthesis of the experimental set-up. Further details are given below.

\subsubsection{Nested discharge measurement network}

In the Gard catchment, two small catchments are instrumented: the Valescure catchment, dominated by granite geology and a forest cover $\left(3.9 \mathrm{~km}^{2}\right)$ with five gauges ${ }^{2}$, and the Tourgueille catchment dominated with a schist geology and a forest cover $\left(10 \mathrm{~km}^{2}\right)$ with three gauges ${ }^{3}$ (see details in Table 2 and Fig. 4). The Avène catchment $\left(60 \mathrm{~km}^{2}\right)$, a tributary of the Gardon d'Alès, has also been equipped with three gauges ${ }^{4}$ (Table 2, Fig. 3). The Avène represents other lithologic and topographic conditions, combining karstic and crystalline rocks upstream (wooded areas), thick carbonated deposits and cultivated areas downstream. The nested subcatchments allow the separate monitoring of each typical landscape, and in particular of a karstic sub-catchment. It should be noted that, although karstic areas have been shown to play an important role in the region (e.g. Delrieu et al., 2005), they are not central to our experimental set-up. We have chosen to rely on data collected in another observatory, the Medyciss observatory ${ }^{5}$, and the corresponding modelling studies of the associated teams to address karstic areas (e.g. Coustau et al., 2012).

In the Ardèche catchment, three nested sub-catchments are gauged: the Gazel catchment $\left(3.4 \mathrm{~km}^{2}\right)$, the Claduègne catchment $\left(43 \mathrm{~km}^{2}\right)$ with a water level plus a flow velocity sensor 6 and the Auzon catchment $\left(116 \mathrm{~km}^{2}\right)$ with an image-based LS-PIV system (large-scale particle image velocimetry; see the details in Sect. 2.4.2).

\footnotetext{
${ }^{2}$ http://mistrals.sedoo.fr/HyMeX/Parameter-search/ ?editDatsId=986\&datsId=986\&project_name $=$ HyMeX

${ }^{3} \mathrm{http}: / /$ mistrals.sedoo.fr/HyMeX/Parameter-search/ ?editDatsId=987\&datsId=987\&project_name=HyMeX

${ }^{4}$ http://mistrals.sedoo.fr/HyMeX/Parameter-search/ ?editDatsId=988\&datsId=988\&project_name $=$ HyMeX

5 http://www.medycyss.org/

${ }^{6} \mathrm{http}: / /$ mistrals.sedoo.fr/HyMeX/Parameter-search/ ?editDatsId=993\&datsId=993\&project_name=HyMeX
} 
For all these stations, it is necessary to gauge the river to establish the stage-discharge relationship. Traditional salt dilution, current meter methods or hydroacoustic profilers are used for low to medium discharges and for floods in small streams only. When higher velocity and flow depth, as well as floating debris, are present, this presents a danger to the operators and the sensors. This typically occurs during floods in medium to large streams. In this case, modern nonintrusive methods, such as surface velocity radars (SVR) (see Sect. 2.5.3), are deployed.

\subsubsection{Limnimeter networks}

The objectives of the limnimeter networks are somewhat different in the Valescure and Claduègne catchments. In the Valescure catchment, the limnimeters and thermo-buttons (temperature sensors) are installed in the $0.6 \mathrm{~km}^{2}$ Cartaou sub-catchment (Fig. 4a), mainly in the intermittent drainage network with a drainage area of 0.01 to $0.3 \mathrm{~km}^{2}$. The objective is to get a yes/no answer to the following question: is there water in the river reach and how long does it last? For the thermo-buttons it is assumed that the water temperature is lower than the air temperature to detect such network activation. The automatic sensors network (time step of $2 \mathrm{~min}$ ) is complemented by field surveys aiming at mapping the extension of the active drainage network before, during and after a rainfall event.

In the Claduègne catchment (Fig. 5), the limnimeter network $^{7}$ has been set up on a larger scale with 11 limnimeters sampling sub-catchments of 0.17 to $2.2 \mathrm{~km}^{2}$, with variability in geology and land use. The sensors are installed mainly in headwater sub-catchments where the landscape properties are homogeneous. The river reaches are also intermittent. When possible, controlled sections are chosen to allow the determination of stage-discharge relationships. The Claduègne catchment has been shown to be located in a region with a high gradient in annual rainfall (e.g. Molinié et al., 2012). In order to get high-resolution rainfall, the catchment is equipped with the HPiconet ${ }^{8}$ dense network of rain gauges (10 gauges; see Fig. 5). During autumn 2012 and 2013, the area was also covered with two research radars (Ducrocq et al., 2014, Fig. 5).

In all these catchments, very high resolution (VHR) lidar digital terrain model (DTM) and satellite images were acquired to accurately determine water pathways on hillslopes and their connectivity with the drainage network (drainage density, distance from a reach), but also the connectivity between hillslopes and potential networks, and the drainage network morphology (width, depth, etc.) (e.g. Sarrazin, 2012). Detailed land cover maps are also being derived from Pléiades or Quickbird images.

\footnotetext{
${ }^{7}$ http://mistrals.sedoo.fr/HyMeX/Parameter-search/ ?editDatsId=994\&datsId=994\&project_name $=$ HyMeX

${ }^{8} \mathrm{http}: / /$ mistrals.sedoo.fr/HyMeX/Parameter-search/ ?editDatsId=656\&datsId=656\&project_name $=$ HyMeX
}

The collected data are useful for doing the following:

1. assess the runoff contribution to the intermittent drainage network

2. detect emergence of runoff at the head of small basins

3. measure the space and time connectivity to the perennial drainage network

4. assess the relative importance of rainfall and landscape spatial variability.

\subsubsection{Geochemistry measurements}

Many studies have shown an interest in using geochemical analysis for the determination of the origin of water and the water pathways. For instance, inter-element ratios including $\mathrm{Ba} / \mathrm{Sr}, \mathrm{Ca} / \mathrm{Sr}, \mathrm{SiO}_{2}$ concentration and ${ }^{87} \mathrm{Sr} /{ }^{87} \mathrm{Sr}$ isotopic ratios are used for studying the relative contributions of soil water and groundwater to stream water discharge during intense rainfall events (Land et al., 2000; Iwagami et al., 2010). Investigations of the spatial and temporal dynamics of dissolved organic carbon (DOC) (Hope et al., 1997) are used to characterize the dominant runoff processes and origin of water fluxes: rapid runoff, soil water (sub-surface flows) and groundwater components (Casper et al., 2003). In this study, the spatial and temporal variability of the water stable isotopes $\left(\delta^{18} \mathrm{O}, \delta \mathrm{D}\right)$ of the rainfall, stream, soil and groundwaters at different timescales (seasonal down to intra-event) are used to do the following:

1. identify the bedrock and soil reservoir dynamics during base flow conditions

2. study the evolution of the different reservoir contributions during and after flood events.

Opportunistic collection of samples of soil water, groundwater and stream water is performed during and after intense rainfall events in the Valescure catchment (see Sect. 2.5.2 and location of samplers in Fig. 4a). In addition, some gauging stations are equipped with continuous measurements of temperature and water electrical conductivity (CTD-Divers; Figs. 4 and 5), which can also provide interesting information about the division of runoff into surface, sub-surface and groundwater flow (e.g. Birkinshaw and Webb, 2010).

\subsubsection{Documentation of the surface hydraulic properties}

A field campaign aiming at documenting the variability of surface hydraulic properties was conducted in May-June 2012 in 17 fields in the Claduègne catchment (Fig. 3 and details in Fig. 7). They were selected from the cross-analysis of pedology, land cover and geology maps following the method of Gonzalez-Sosa et al. (2010). The tested hypothesis is that land use has a major influence on the observed 
Table 2. Small to medium catchments monitoring. CTD-Divers measures conductivity, temperature and water pressure.

\begin{tabular}{|c|c|c|c|c|}
\hline Catchments & Valescure & Tourgueille & Avène & Gazel/Claduègne/Auzon \\
\hline $\begin{array}{l}\text { Catchment } \\
\text { characteristics }\end{array}$ & $\begin{array}{l}\text { Steep slopes, } \\
\text { natural vegetation, } \\
\text { granite bedrock }\end{array}$ & $\begin{array}{l}\text { Steep slopes, } \\
\text { natural vegetation, } \\
\text { schist bedrock }\end{array}$ & $\begin{array}{l}\text { Upstream wooded areas } \\
\text { on karstic and crystalline } \\
\text { rocks; downstream } \\
\text { cultivated areas on thick } \\
\text { carbonated deposits }\end{array}$ & $\begin{array}{l}\text { Moderate slopes, } \\
\text { cultivated area } \\
\text { (vineyard, pasture), } \\
\text { sedimentary clay } \\
\text { limestone bedrock }\end{array}$ \\
\hline $\begin{array}{l}\text { Dominant processes } \\
\text { expected }\end{array}$ & $\begin{array}{l}\text { Saturation-excess runoff, } \\
\text { sub-surface flow }\end{array}$ & $\begin{array}{l}\text { Saturation-excess runoff, } \\
\text { sub-surface flow }\end{array}$ & Unknown & $\begin{array}{l}\text { Surface flow on cultivated areas, } \\
\text { unknown on pastures or forests }\end{array}$ \\
\hline Rain gauges & five gauges and one disdrometer & two gauges and one disdrometer & three gauges & HPiconet on Gazel/Claduègne \\
\hline $\begin{array}{l}\text { Discharge gauging } \\
\text { stations }\end{array}$ & $0.3,0.5,0.6,0.9,3.9 \mathrm{~km}^{2}$ & $1,2.5,10 \mathrm{~km}^{2}$ & $10,21,60 \mathrm{~km}^{2}$ & $\begin{array}{l}3 \text { (Gazel), } 43 \text { (Claduègne), } \\
116 \text { (Auzon) } \mathrm{km}^{2}\end{array}$ \\
\hline $\begin{array}{l}\text { Limnimeter } \\
\text { network }\end{array}$ & $\begin{array}{l}5 \text { limnimeters, } 18 \text { thermo-buttons } \\
\text { and survey of gullies during } \\
\text { and after events in } \\
\text { the } 0.3 \mathrm{~km}^{2} \text { sub-catchment }\end{array}$ & None & None & $\begin{array}{l}11 \text { limnimeters ( } 7 \text { mini-Diver } \\
\text { and } 4 \text { CTD-Divers) in } \\
\text { the Claduègne catchment }\end{array}$ \\
\hline Geochemistry & $\begin{array}{l}\text { Sampling of rainfall, } \\
\text { soil and groundwater } \\
\text { during events and continuous } \\
\text { conductivity at the outlet }\end{array}$ & $\begin{array}{l}\text { Continuous temperature } \\
\text { and conductivity } \\
\text { at the outlet }\end{array}$ & None & $\begin{array}{l}\text { Continuous temperature and } \\
\text { conductivity (Gazel, Claduègne) } \\
\text { and four limnimeters with electrical } \\
\text { conductivity and temperature }\end{array}$ \\
\hline $\begin{array}{l}\text { Infiltration } \\
\text { tests }\end{array}$ & $\begin{array}{l}\text { Performed during } \\
\text { hillslope monitoring }\end{array}$ & Collection of existing data & $\begin{array}{l}\text { Collection of } \\
\text { existing data }\end{array}$ & $\begin{array}{l}17 \text { sampled fields using } \\
\text { infiltrometers and Beerkan }\end{array}$ \\
\hline DEM & $1 \mathrm{~m}$ lidar DEM & $1 \mathrm{~m}$ lidar DEM & $1 \mathrm{~m}$ lidar DEM & $\begin{array}{l}1 \text { m lidar DEM (Gazel, Claduègne), } \\
25 \text { m DEM (Auzon) }\end{array}$ \\
\hline Pedology & $\begin{array}{l}\text { Languedoc-Roussillon soil } \\
\text { database and landscape } \\
\text { segments locally }\end{array}$ & $\begin{array}{l}\text { Languedoc-Roussillon } \\
\text { soil database }\end{array}$ & $\begin{array}{l}\text { Languedoc-Roussillon } \\
\text { soil database }\end{array}$ & Ardèche soil database \\
\hline $\begin{array}{l}\text { Vegetation map } \\
\text { (summer and winter) }\end{array}$ & $\begin{array}{l}\text { Detailed land use map } \\
\text { based on Pléiades images }\end{array}$ & $\begin{array}{l}\text { Detailed land use map } \\
\text { based on Pléiades images }\end{array}$ & $\begin{array}{l}\text { Detailed land use map } \\
\text { based on Pléiades images }\end{array}$ & $\begin{array}{l}\text { Detailed land use map } \\
\text { based on Quickbird images } \\
\text { (Gazel, Claduègne); } \\
\text { Landsat images (Auzon) }\end{array}$ \\
\hline
\end{tabular}

hydraulic properties rather than the soil texture. Two types of infiltration tests were performed: positive head infiltration tests in $40 \mathrm{~cm}$ diameter cylinders (three replicates) and suction $(-20 \mathrm{~mm})$ infiltration tests using mini-disk infiltrometers 4.5 or $8 \mathrm{~cm}$ in diameter (Decagon Devices Inc., Pullman, WA) (zero to two replicates). The infiltration tests were complemented with particle size data analysis, including coarse fragments. The infiltration tests are analysed using the Lassabatère et al. (2006) and the Vandervaere et al. (2000) methods to get more robust results. A comparison of in situ estimates and various pedo-transfer functions is scheduled. Special attention is paid to accounting for coarse fragments (Fies et al., 2002) and the impact of macropores in enhancing hydraulic conductivity close to saturation (e.g. Schwartz et al., 2003; Gonzalez-Sosa et al., 2010).

\subsubsection{Data analysis methods}

Various approaches are considered for analysing the spatial and temporal patterns of the hydrological response at the different scales. They have not been implemented yet as data collection is ongoing, but the aim is to highlight the main factors controlling the catchment behaviour and signatures of the rainfall-runoff relationship across scales (Beighley

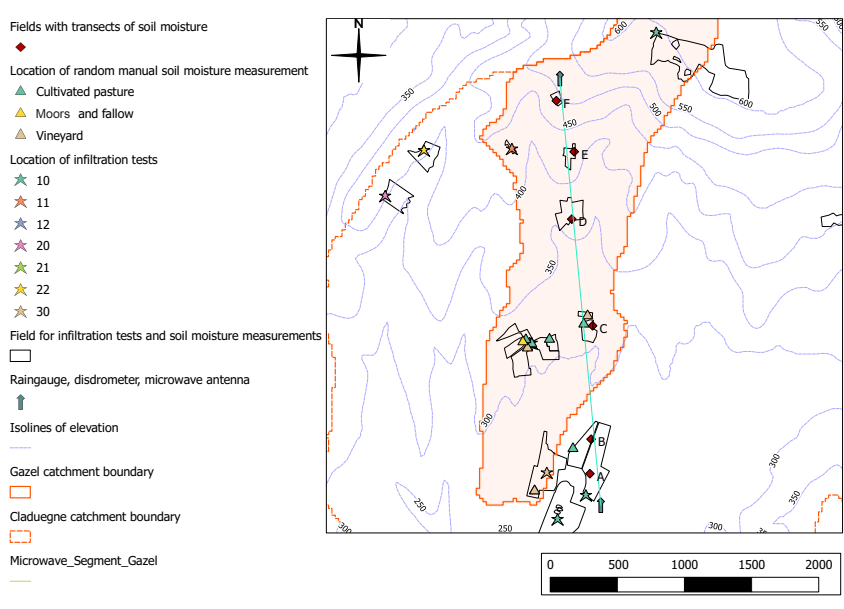

Figure 7. Location of soil moisture measurements during SOP1 in the Gazel catchment. Detail of the location and land use of the infiltration tests is also visible.

et al., 2005; Gupta et al., 2008; Coopersmith et al., 2012). For the small catchments, rising and falling limbs of limnimeter data and transfer times of runoff will be analysed in relation to rainfall characteristics and initial soil moisture (Sarrazin, 
2012). Sivapalan (2003b) and McDonnell et al. (2010) point out the interest of travel time distributions that are particularly suited to the analysis of the limnimeter and lidar DTM data. They allow testing hypotheses about connected and unconnected parts of the catchment (Sarrazin, 2012).

For the rainfall/discharge data, several methods, summarizing the catchment behaviour, will be implemented, such as flow duration curves (Vázquez et al., 2008; Willems, 2009), and recession analysis to derive storage-discharge relationships (Kirchner, 2009). Statistical approaches (Ali et al., 2010, 2012a, b) can relate the hydrological response to explanatory variables that are representative of a scale (rainfall characteristics, lithology, land use, rainfall parameters, initial soil moisture, soil properties, slope). Bayesian networks (Maes et al., 2007) as well as fractal analysis based on lidar DTM (Martin et al., 2014) are also tested for better flash flood understanding. The analysis particularly focuses on identifying whether the relationships between observed factors on one scale are identical on other scales and whether fractal approaches can provide invariant descriptors which can be compared between catchments (Forriez et al., 2011).

\subsection{Large catchments}

On this scale, the observation mainly relies on operational networks and it is complemented by research observations during the EOP (enhanced observation period) (Fig. 3). On this scale and at the lowest ones, one of the main objectives is to improve the spatial and temporal resolution of rainfall fields and to quantify their uncertainty. For discharge measurements, the objective is to improve the estimation of the stage-discharge relationship, especially during high-water conditions, using innovative non-intrusive methods, and to quantify the discharge uncertainty and how it propagates into hydrographs or the water balance. Given the high space and time variability of rainfall (e.g. Molinié et al., 2012) associated with flash floods, accurate rainfall and discharge data are crucial to improving our understanding of the process through data mining, as well as to obtaining accurate input forcing and evaluation data for regional hydrological models (Borga et al., 2008; Bouilloud et al., 2010).

\subsubsection{Rainfall estimation}

Since 2000, OHM-CV collects, critically analyses and performs rainfall re-analyses with the data sets from the operational rain gauge networks operated by Météo-France (MF), Service de Prévision des Crues Grand Delta and Electricité de France (252 hourly gauges complemented with 160 daily rain gauges) and the four MF weather radars located at Nimes, Bollène, Sembadel and St Nizier (Fig. 3). A radar data processing system called TRADHy (Traitements des données radar pour l'hydrologie) has been developed (Delrieu et al., 2009; Bouilloud et al., 2010) with a geostatistical framework for assessing the quality of the radar quan- titative precipitation estimations (QPEs) (Kirstetter et al., 2010; Delrieu et al., 2014a). Results show that radar QPE quality is good over the entire region of interest in the case of deep convection but the "hydrologic visibility" (Pellarin et al., 2002) is rather poor in the mountainous part of the Cévennes-Vivarais region both in the winter season and for the long-lasting shallow convective events of the autumn. The latter events are less critical in terms of flash flood generation due to their moderate intensities, but they produce large rainfall amounts (up to $100 \mathrm{~mm}$ in a few days; Godart et al., 2011) that increase the initial soil moisture. In order to improve rainfall estimation, enhanced rainfall observation capabilities were deployed during the HyMeX SOP1 (Ducrocq et al., 2014): 2 X-band Doppler-polarimetric radars, 2 noncoherent fast-scanning X-band radars, 23 disdrometers and a number of additional rain gauges networks, which were installed in the mountainous parts of the Ardèche and Gard watersheds (Fig. 3). Most of this additional set-up was operated during autumn 2013 as well. This allows a unique reinforcement of the operational observation system and the possibility to investigate rainfall variability on the very short spatial and temporal scales relevant for the analysis of flash flood generation processes on all scales.

A rainfall reanalysis prototype was derived for year 2008 (Delrieu et al., 2013) and recently extended to the 20072012 period. It relies on $5 \mathrm{~min}$ operational radar data and $1 \mathrm{~h}$ rain gauges amounts. Rainfall fields are provided on a daily timescale and $1 \mathrm{~km}^{2}$ resolution grid using kriging interpolation for each single day of the year. For the most significant rain events, two additional products are provided:

1. radar rainfall fields with a 5 min time step at $1 \mathrm{~km}^{2}$ resolution grid

2. hourly rainfall amounts combining radar and rain gauges using kriging with external drift (KED) on $1 \mathrm{~km}^{2}$ resolution grids or hydrological meshes (subcatchments) from 5 to $300 \mathrm{~km}^{2}$.

A more detailed reanalysis will be performed for the HyMeX EOP (2012-2015) using the additional rain gauges and research radars, with a finer grid $(100 \mathrm{~m})$ and time (15 $\mathrm{min})$ resolutions.

For the quantification of rainfall uncertainty, two approaches are considered. The first one relies on a statistical analysis of rainfall errors

1. using rain gauge data to establish reference rain amounts for the radar-only estimates (Kirstetter et al., 2010; Delrieu et al., 2014a) and

2. through a novel approach exploiting the Kriging estimation variances for the rain gauge and radar-rain-gauge merging estimates.

The radar errors, analysed conditionally with respect to the rain intensity thanks to generalized additive models for 
location, scale and shape (GAMLSS), are shown to be radarrange- and rainfall-type-dependent (Delrieu et al., 2014a). The KED estimates are shown to be systematically more accurate than the estimates provided by the radars and the rain gauge network considered separately. By comparing the rain gauge ordinary kriging errors and the KED ones, the added value of the radar proved also to be most important for the smallest space-time scales, those of interest for a flash flood generation study. The next step will be the implementation of a stochastic simulator to generate ensembles of plausible rainfall time series, derived from the re-analyses and the associated error models, for use as inputs in distributed hydrological models.

The second approach is based on a geostatistical spacetime rainfall generator (Lepioufle et al., 2012; Leblois and Creutin, 2013), based on the turning-band method (Matheron, 1973). The rainfall fields are classified into rainfall classes based on a Kohonen classification. Each class is considered as statistically homogeneous. For each class, the spatial structure of rainfall is estimated jointly on all time steps relevant to the class. In the case successive time steps are within the same class, information is also gained about the temporal structure of the rainfall. The rainfall simulator has been adapted to be conditioned to observed rain gauge data to produce several realizations of rainfall fields, respecting the values observed at the rain gauges locations and reflecting the rainfall uncertainty at the other points (example used in Renard et al., 2011). Typical target resolution is $1 \mathrm{~km}^{2}$ and $1 \mathrm{~h}$. New ongoing developments include the generation of rainfall fields in non-homogeneous zones (related to topography in the case of the Cévennes-Vivarais region), based on concomitance of local Kohonen-derived rainfall classes in various subregions (Ollagnier, 2013). Resulting region-wide rainfall patterns exhibit a useable concomitance with independent classes of atmospheric synoptic situations.

\subsubsection{Discharge measurements}

The primary source of information about discharges comes from the hydrological services of different organizations (Fig. 3). This operational network only covers watershed larger than about $50-100 \mathrm{~km}^{2}$. A major limitation comes from the often poor documentation of the rating curves for high and extreme discharges due to the impracticability of classical gauging techniques during floods. To progress in this matter, LS-PIV stations (Le Coz et al., 2010) were developed and installed over several gauging stations (allowing for cross control of discharge estimation between methods) and at new locations ${ }^{9}$ (Fig. 3). In the system described by Le Coz et al. (2010), images were recorded continuously even without floods and the water level was recorded within the images. However, it was only available during floods as

\footnotetext{
${ }^{9}$ http://mistrals.sedoo.fr/HyMeX/Parameter-search/ ?editDatsId=996\&datsId=996\& project_name $=$ HyMeX
}

the images were destroyed automatically in the absence of significant events. The system was improved to record independently and continuously the water level with a $5 \mathrm{~min}$ time step. Images for LS-PIV analyses are recorded once a specified water level threshold is exceeded. LS-PIV gauging stations provide discharge estimations for high flows far beyond the values recorded using standard gauging methods, and they automatically record all floods occurring by daytime, even the fastest ones. Methods are also developed to exploit non-professional movies of flooding rivers, and a procedure is proposed to volunteers on the FloodScale project website $^{10}$ (Le Boursicaud et al., 2014). LS-PIV and SVR are non-contact techniques providing the flow velocity at the free surface only, which requires the additional use of an appropriate depth-average-to-surface-velocity ratio in order to compute discharge (see Le Coz et al., 2010, for a discussion of coefficient values). Also, a bathymetry cross section profile must be determined based on pre- and post-flood surveys. It is important to study the morphodynamical evolution of the stream during the flood in order to assess the additional discharge uncertainty due to possible bed changes.

The additional flood discharge gaugings obtained thanks to LS-PIV or SVR (see Sect. 2.5.3) are incorporated into a Bayesian inference framework for establishing stagedischarge relationships and for rigorously estimating the associated uncertainty. A methodology, called BaRatin (BAyesian RATINg curve) (Le Coz et al., 2014), and some tools have been developed to analyse stationary rating curves, i.e. assuming that the stage-discharge relationship is stable over the period under consideration. The method can be decomposed into three main steps:

1. determination of hydraulic priors from the hydraulic analysis of the gauging site, possibly complemented by numerical modelling

2. review and validation of existing stream gaugings. An uncertainty is associated with each of them using conventional and original methods (Le Coz et al., 2012), and this is taken into account in the estimation of the rating curve

3. Bayesian inference and simulation of a set of plausible curves.

Up to now, the method has been applied to the Ardèche catchment gauging stations, including all types of existing gaugings and to the research stations operated by the involved research teams, providing the most probable stagedischarge relationship and the associated $95 \%$ uncertainty. Ongoing work deals with the propagation of all the sources

\footnotetext{
${ }^{10} \mathrm{http} / / /$ floodscale.irstea.fr/donnees-en/ videos-amateurs-de-rivieres-en-crue/ videos-amateurs-de-rivieres-en-crue
} 
of uncertainty in hydrographs. A software implementing the method has been developed and is distributed for free ${ }^{11}$.

\subsection{Opportunistic observations}

During HyMeX SOP1, three types of opportunistic observations were performed: manual soil moisture measurements to document its evolution before, during and between events in the Gazel catchments; geochemistry sampling of rainfall, river and soil waters, as well as field survey of gully activation in the Valescure catchment; and discharge measurements of flooding rivers using SVR in the Ardèche and Gard catchments. The opportunity of sending teams into the field is determined thanks to a real-time warning system, which is deployed in autumn, based on the analysis of information made available on the HyMeX SOP website. During HyMeX SOP1, this task was performed by professional meteorological forecasters from Météo-France (Ducrocq et al., 2014), but in 2013 and the autumn of the other years, the forecasting was and will be performed by non-professional volunteers, with the help of AROME (Applications of Research to Operations at MEsoscale) meteorological forecasts, hydrological forecasts from operational services, as well as nearreal-time rainfall gauges and radar image data provided by Météo-France. The availability of near-real-time radar data is also very useful for guiding the teams towards the most interesting areas, once they are in the field. Unfortunately, as shown by Ducrocq et al. (2014), our region of interest was one of the less affected by high rainfall events during HyMeX SOP1, with maximum daily rainfall of 75-100 mm, whereas values of up to $300 \mathrm{~mm} \mathrm{day}^{-1}$ were recorded in other areas of the western Mediterranean. Nevertheless, these events allowed the testing of the efficiency of the warning protocols and made it possible to improve them for the next falls. The detail of the opportunistic observations performed in 2012 is given below. All the opportunistic measurements will be continued in the autumn of the coming years (2013-2015).

\subsubsection{Soil moisture measurements during HyMeX SOP1}

Opportunistic observations of soil moisture were performed on two scales (field and small catchment) during HyMeX SOP1 (autumn 2012) in the Gazel small catchment (Fig. 7). In the absence of continuous measurements in that catchment (which only started in spring 2013), the objective was to document soil moisture status before, during and after major rainfall events. Two protocols were set up. The first one relies on random soil moisture measurements (10-14 points per field) using a capacitive sensor (Delta T, SM 200). Ten sites were sampled (four pastures, four vineyards, one fallow and one bare-soil field; see triangles in Fig. 7). Due to time constraints and the difficulty to anticipate rainfall events well

\footnotetext{
${ }^{11}$ https://forge.irstea.fr/projects/baratin
}

in advance, only six dates were sampled (23, 24, 26 September; 10, 25, 26 November).

In the second protocol, six fields located along a transect (corresponding to the installation of a microwave link during SOP1) were selected, with increasing altitude from site A to $\mathrm{F}$ (from about 250-525 m) (red diamonds in Fig. 7). Within each field, a $50 \mathrm{~m}$ long transect was defined and soil moisture measurements were taken every $2 \mathrm{~m}$ using a ThetaProbe unit (Delta-T device). Between 14 September and 5 December 2012, 16 dates were sampled. Details are provided in Huza et al. (2014).

\subsubsection{Event monitoring (geochemistry sampling and gullies activation survey)}

During HyMeX SOP1, three significant events were recorded in the Valescure catchment: 24 September $(50 \mathrm{~mm}), 26$ October $(115 \mathrm{~mm})$ and $9-10$ November $(93 \mathrm{~mm})$. The last two events were sampled for geochemical analyses using automatic samplers (see location in Fig. 4a). The samplers have to be launched manually before the beginning of the event. Two automatic 24-bottle samplers sample stream water and rainfall respectively. Ten Tensiometers Tensionic and three lysimeters are also deployed for soil water sampling. Regular sampling is also performed monthly in five stream water points over the Valescure catchment. Measurements concern physico-chemical parameters $(\mathrm{pH}$, electrical conductivity, temperature, $\mathrm{Na}, \mathrm{Ca}, \mathrm{K}, \mathrm{Mg}, \mathrm{NH}_{4}, \mathrm{~F}, \mathrm{Ci}, \mathrm{NO}_{3}$, $\mathrm{SO}_{4}$, alkalinity $\mathrm{HCO}_{3}^{-}+\mathrm{CO}_{3}^{2-}$ ), stable isotopes of the water $\left({ }^{18} \mathrm{O} /{ }^{16} \mathrm{O},{ }^{2} \mathrm{H} /{ }^{1} \mathrm{H}\right.$ ), total and dissolved organic carbon (TOC and DOC) and trace elements ( $\mathrm{Li}, \mathrm{B}, \mathrm{Al}, \mathrm{Si}, \mathrm{Ti}, \mathrm{V}, \mathrm{Cr}, \mathrm{Mn}, \mathrm{Fe}$, $\mathrm{Co}, \mathrm{Ni}, \mathrm{Cu}, \mathrm{Zn}, \mathrm{As}, \mathrm{Rb}, \mathrm{Sr}, \mathrm{Mo}, \mathrm{Cd}, \mathrm{Sb}, \mathrm{Cs}, \mathrm{Ba}, \mathrm{La}, \mathrm{Ce}, \mathrm{TI}$, $\mathrm{Pb}, \mathrm{Th}, \mathrm{U})$. All analyses are performed at the HydroSciences Montpellier analytical platforms.

Field survey complementing the automatic limnimeters and thermo-buttons networks were performed for the 24 September, 26 October and 9-10 November events. A series of maps was produced, showing the active hydrographic network before, during and after each event (see examples in Sect. 4.2).

\subsubsection{Stream gauging during floods}

When an important event is forecasted several teams of two people are sent to the field in order to gauge flooding rivers at pre-selected sections (the operational and research stations in Fig. 3; gauging is always undertaken from a bridge). For the largest sections, the teams are equipped with surface velocimetry radars (SVR) (Fig. 8a), which are used to measure the surface flow velocity, pointing upstream (Fig. 8b) at 13 positions across the section (see Fig. 8c). The water level must also be measured at the time of the measurement. The technique allows measuring surface flow velocities safely and rapidly. Combined with pre- and/or post-event bed geometry surveys, it yields useful stream gauging data 

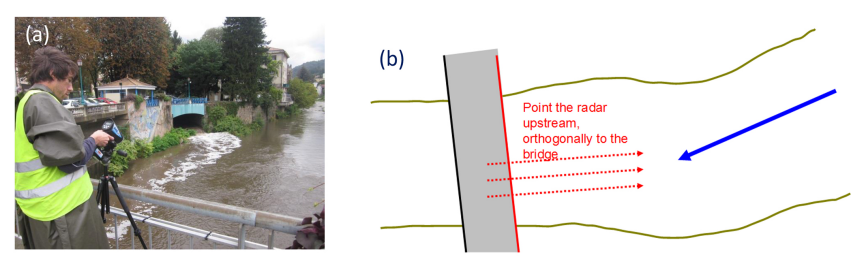

(c)

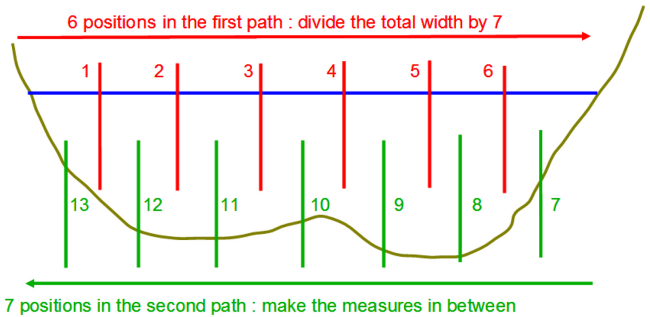

Figure 8. (a) Photo of a measurement performed with a surface velocimetry radar (SVR); (b) position of the measurement transect relative to the bridge; (c) location of the positions within the section where measurements are carried out.

for sections not documented otherwise or for discharge values which cannot be measured with standard intrusive methods (Dramais et al., 2013). For the smallest sections, salt dilution methods are used.

\section{Modelling strategy}

\subsection{Introduction}

The main objective of the modelling effort is to formalize the understanding and knowledge of the main hydrological processes at play, between and during flash floods on various spatial scales and to hierarchically organize the dominant processes and interactions between them. The modelling strategy adopted thus belongs to a "hypothesis testing" framework, as described by Morin et al. (2006), Zehe et al. (2006) or Clark et al. (2011) (see Fig. 2), rather than to a more operational framework such as flood forecasting. Several modelling approaches are developed and compared, on the scale of small catchments of a few $\mathrm{km}^{2}$ and on the regional scale of large catchments. The models developed in the study use different assumptions and representations of hydrological processes, following both bottom-up and top-down approaches, as defined by Sivapalan (2003a). The bottom-up approach consists of generalizing on larger scales simplifying assumptions of linearity and/or boundary value problems based on partial differential equations established on small scales. This leads to the identification and calibration of "effective parameters" which are sometimes difficult to link with measurable quantities (Sivapalan, 2003a), although recent methods combining the use of small-scale parameters variability and regionalization techniques were shown to be more efficient in preserving spatial patterns of variability (Samaniego et al., 2010; Douvinet et al., 2013). The top-down approach consists of deriving "emergent properties" (Sivapalan, 2003b) or "functional traits" (McDonnell et al., 2007), from a combination of data analysis and process conceptualization (e.g. Kirchner, 2006), across scales. Approaches based on statistical methods (Ali et al., 2010), or data interpretation by segmentation of the rainfall-discharge time series (Latron et al., 2008; Kirchner, 2009; Willems, 2009; Furusho et al., 2014), can also be used. Both the top-down and bottom-up approaches are complementary and their comparison can help understand the main drivers of the functioning of the system.

In agreement with the hypothesis testing framework, most of the models used in our study are developed within modelling frameworks, such as JAMS (Jena Adaptable Modelling System) (Kralisch et al., 2007) and LIQUID (Viallet et al., 2006; Branger et al., 2010). These modelling tools allow us to build "à la carte" models and to incrementally assess the impact of changing one hypothesis, either in terms of process representation or in terms of parameter specification. Calibration is also avoided as much as possible in order to obtain direct links between the simulated processes and the available data (Kirchner, 2006).

A key point in the model application is also the catchment discretization. The latter aims at defining the "functional units", based on the available information on the various scales. Many approaches have been proposed in the literature in terms of spatial discretization (e.g. Wood et al., 1988; Flügel, 1995; Reggiani et al., 1998; Dehotin and Braud, 2008). These "homogeneous" units should reflect the hydrological behaviour: production of infiltration excess runoff, saturation excess (Schmocker-Fackel et al., 2007), storage, transfer or accumulation zones (Lin et al., 2006a, b), surface, sub-surface or groundwater flow (Latron and Gallart, 2007; Rogger et al., 2012) and their connectivity (SchmockerFackel et al., 2007; Lin, 2010). The approach used in this study is built on those papers and it combines image analysis and field work to derive such functional units.

\subsection{Small catchment modelling}

On this scale, the objective of the modelling studies is to build models able to represent the diversity of observed catchment behaviours and to simulate the main processes as evidenced by observations. The models are used here as "hypothesis testing tools" in order to understand the impact of different modelling choices, process representation, parameter specification on the hydrological responses and to retain the hypotheses which are the most in agreement with the observed behaviour and/or synthesis of observation. This is ongoing work and only the principles are given here.

The first modelling approach is built on the CVN model (Anquetin et al., 2010; Braud et al., 2010), developed within the LIQUID modelling framework. It discretizes the landscape into irregular hydro-landscapes (Dehotin and Braud, 
2008). Infiltration and water redistribution are modelled using an efficient solution of the Richards equation (Ross, 2003; Varado et al., 2006b) with hydraulic properties described using standard pedo-transfer functions (Rawls and Brakensiek, 1985). The model takes into account the vertical heterogeneity of soil hydraulic properties as described in the available soil databases. Excess runoff is instantaneously directed towards the closest river reach where water flow is modelled using the kinematic wave equation. Evapotranspiration components have also been added in order to provide continuous simulations (Vannier, 2013). The model will be enriched step by step (e.g. Fenicia et al., 2008) to test the following hypotheses:

1. Does the improved description of soil hydraulic properties, as derived from in situ observations, improve the realism of model simulations?

2. Does the inclusion of sub-surface flow improve the simulation of inter-event processes and initial conditions before events?

3. What is the impact of the choice of different spatial discretization or functional units definition on the model results?

4. What is the relative impact of rainfall and landscape spatial variability on different scales?

A second approach uses the RuiCells model (Douvinet et al., 2013). This cellular automaton assesses, in a bottomup and step-by-step approach, the sensitivity of the surface flow dynamics to rainfall intensity, infiltration excess, land use or topography. As this model only simulates surface runoff, possible mismatch with observations can be a diagnostic of the importance of sub-surface flow. For the small catchments, the model implements lidar DEM. The model thus allows the mapping of surface flow concentration, taking into account possible soil erosion and threshold effect and provides estimation of peak flow discharges and cumulative runoff amounts, according to the catchment morphology. It can also help in quantifying surface transfer time and possible reinfiltration before reaching a network; this quantification is undertaken in order to determine if this process should be included in the CVN model. Running the model on several catchments with similar input data allows the definition of indices and measures that can be used to compare catchments (Douvinet et al., 2013).

\subsection{Regional-scale modelling}

The specific objective of regional modelling is to represent the main hydrological processes on large territories (several thousands of $\mathrm{km}^{2}$ ) and to be able to simulate not only discharge at large catchment outlets, but also the hydrological variables on intermediate scales consistent with flash flood dynamics (mostly a few $\mathrm{km}^{2}$ ). This necessitates the building of distributed hydrological models with simplified process representations as compared to the approach described before (Sect. 3.2), but with a good process representation on sub-catchments of a few $\mathrm{km}^{2}$. Another difficulty of this modelling task is that we can no longer rely only on experimental catchment data, but have to work with data from the operational observation networks. These operational networks have their own objectives which may differ from our research concerns. For example, the operational discharge stations on our catchments are designed for flood forecasting and thus are not much concerned with the accuracy of measurements during inter-event periods. Consequently, analyses of the available rainfall-discharge time series are performed to check the consistency of the rainfall and runoff volumes (behaviour across nested catchments, evolution during the rainy season, etc.) and take into account their uncertainty. In addition, various metrics are computed with the aim of characterizing the spatial and temporal variability of rainfall within the catchments (e.g. Zanon et al., 2010). Analytical models (e.g. Viglione et al., 2010a) and/or simple hydrological models may also be considered to better characterize the spatially variable hydrological response as a function of the spatial rainfall and the measured discharge.

The approach implemented first is a bottom-up approach (Sivapalan, 2003a, 2009; Blöschl, 2006) in which hydrological processes are modelled on the scale of small hydrological response units, based on the CVN model presented in the previous section and the iterative approach illustrated in Fig. 2 (Vannier, 2013). The second approach consists of distributing the top-down approach presented by Kirchner (2009) on sub-catchments of a few $\mathrm{km}^{2}$; in this approach each catchment is considered as a single dynamical system. The model formulation is directly derived from the data analysis, retaining the main features of the sub-grid variability and the dominant processes (Zehe et al., 2006). This model is enriched with an explicit representation of routing in the hydrographic network and is currently being implemented within the JAMS framework. As a third complementary approach, the J2000 model (Krause et al., 2006), implemented in the JAMS platform, is also run in parallel in order to provide insight into the meaning of the parameters identified using the bottom-up approach.

In addition, following the example of Bonnifait et al. (2009), who used the CARIMA hydraulic model with the discharge simulated by n-TOPMODEL (TOPography-based hydrological MODEL) (Saulnier and Le Lay, 2009) and showed that the Gorge of the Gardon and its floodplain were very influential in the hydrograph dynamics downstream, the use of a 1-D hydrodynamic model to represent flow routing in the channel network will also be implemented and coupled to the hydrological models. As the influence of river bed topography and river engineering facilities on flow routing within the river network becomes dominant on the hydrograph dynamics when the catchment reaches a certain size 
(Brath and Montanari, 2000), we expect an improved simulation of hydrograph dynamics and water heights.

A comparative analysis of the spatial and temporal scales on which the different approaches provide consistent and/or relevant information will be conducted. The objective is to assess which information and results are usable for each approach on the various scales. This requires working on adequate metrics, necessary to assess the similarity between model simulations and observations, especially for flash floods where the Nash-Sutcliffe efficiency coefficient, traditionally used, may not be appropriate (Jachner et al., 2007; Gupta et al., 2008; Moussa, 2010). As much as possible, hydrological signatures (Gupta et al., 2008; Willems, 2009; Clark et al., 2011), as derived from the data analysis will be used. A multi-site and multi-variable evaluation (Varado et al., 2006a; Moussa et al., 2007) will be performed. In addition, the use of uncertain observed data to evaluate and compare several modelling scenarios raises significant methodological challenges because model evaluation entails comparing two time series of distributions, as opposed to two times series of values. Innovative comparison schemes will be developed for this purpose, following approaches proposed by the probabilistic-forecasting community (e.g. Laio and Tamea, 2007).

\section{Results}

In this section, we illustrate how the currently available observations and models provide interesting insight into the following questions:

1. What is the temporal variability of soil moisture during HyMeX SOP1 and is the variability consistent across scales?

2. What are the active hydrological processes on different spatial and temporal scales during the 9-11 November 2012 event?

3. How can we decrease rainfall and discharge estimation uncertainty?

4. Which information about dominant regional-scale processes can be derived from the combination of data analysis and modelling?

\subsection{What is the temporal variability of soil moisture during HyMeX SOP1 in relation to the hydrological response and is this variability consistent across scales?}

Figure 9a shows the time evolution of local soil moisture (at one point in transect $\mathrm{T} 2$ - see location in Fig. 4a) at depths of 20 and $40 \mathrm{~cm}$ between 1 September and 5 December 2012. The figure also provides the daily rainfall in the middle of the Valescure catchment, as well as the instantaneous discharge at the catchment outlet. Before mid-October, soil moisture increases rapidly in response to rainfall, but returns to low values (between 10 and $15 \%$ ) within 15 days (note that a significant event occurred on 28-30 August $(81 \mathrm{~mm})$ which explains the high values at the beginning of the period. After the 26 October event $(115 \mathrm{~mm})$, soil moisture still decreases after the rainfall event but remains higher than about $25 \%$. The cumulative rainfall since the beginning of the SOP (including the 28-30 August and 26 October events) reaches about $400 \mathrm{~mm}$. The discharge time series follows the same temporal pattern as soil moisture, with a very significant response once the soil remains wet, accompanied by a larger base flow (about 50-100 $\mathrm{L} \mathrm{s}^{-1}$ ). However, the maximum peak discharge registered during SOP1 is moderate $\left(2.35 \mathrm{~m}^{3} \mathrm{~s}^{-1}\right)$ when compared to the maximum value since the beginning of the measurements in 2003 of $12.5 \mathrm{~m}^{3} \mathrm{~s}^{-1}$, registered in October 2006.

Figure $9 \mathrm{~b}$ shows the same figure but with soil moisture measured manually on the small catchment scale (Gazel, $3 \mathrm{~km}^{2}$ ). At each date, the soil moisture data is the average of the 6 transects $\times 25$ measurements transect ${ }^{-1}$ (red squares) or the average of all the random manual measurements performed within the 10 fields (see locations in Fig. 7). Soil moisture is low at the start of SOP1 (about 12\%) and increased rapidly after the first rainfall events to reach values around $25-30 \%$. There is no measurement available to see which value is reached when it dries. At the end of the period, values larger than $30 \%$ are reached. In terms of discharge, the Gazel river is almost dry until the end of October (less than $1 \mathrm{~L} \mathrm{~s}^{-1}$ ). The 26 October event only moderately affects this catchment, but the discharge increases to about $10 \mathrm{~L} \mathrm{~s}^{-1}$. It is necessary to wait until the 9-10 November event $(65 \mathrm{~mm}$ at Le Pradel) to measure a significant response in the river, with discharge reaching $1 \mathrm{~m}^{3} \mathrm{~s}^{-1}$. After this event, a base flow of about $10 \mathrm{~L} \mathrm{~s}^{-1}$ continues to flow into the river. The next event (26-27 November) only brings $43 \mathrm{~mm}$ of rainfall in the Gazel catchment. But this is sufficient to trigger a response similar to that of the previous event with less rainfall. Huza et al. (2014) show that, after the catchment soil moisture reaches a threshold of about $22 \%$, a significant response with a larger runoff coefficient is obtained. This threshold is very close to the $25 \%$ observed locally in the Valescure catchment.

Figure 10 shows maps of the soil wetness index (SWI) over the south-east France domain from September to November 2012, as calculated operationally by MétéoFrance from outputs of the SAFRAN-ISBA-MODCOU ${ }^{12}$ hydrometeorological chain (Habets et al., 2008). Figure 9c shows the discharge at the main outlets of the Gard and Ardèche catchments for the same period. Figure 10a-c show that, in the Gard and Ardèche catchments, the soils are very

\footnotetext{
${ }^{12}$ Système d'analyse fournissant des renseignements atmosphériques à la neige-Interactions between Soil, Biosphere, and Atmosphere-MODCOU
} 

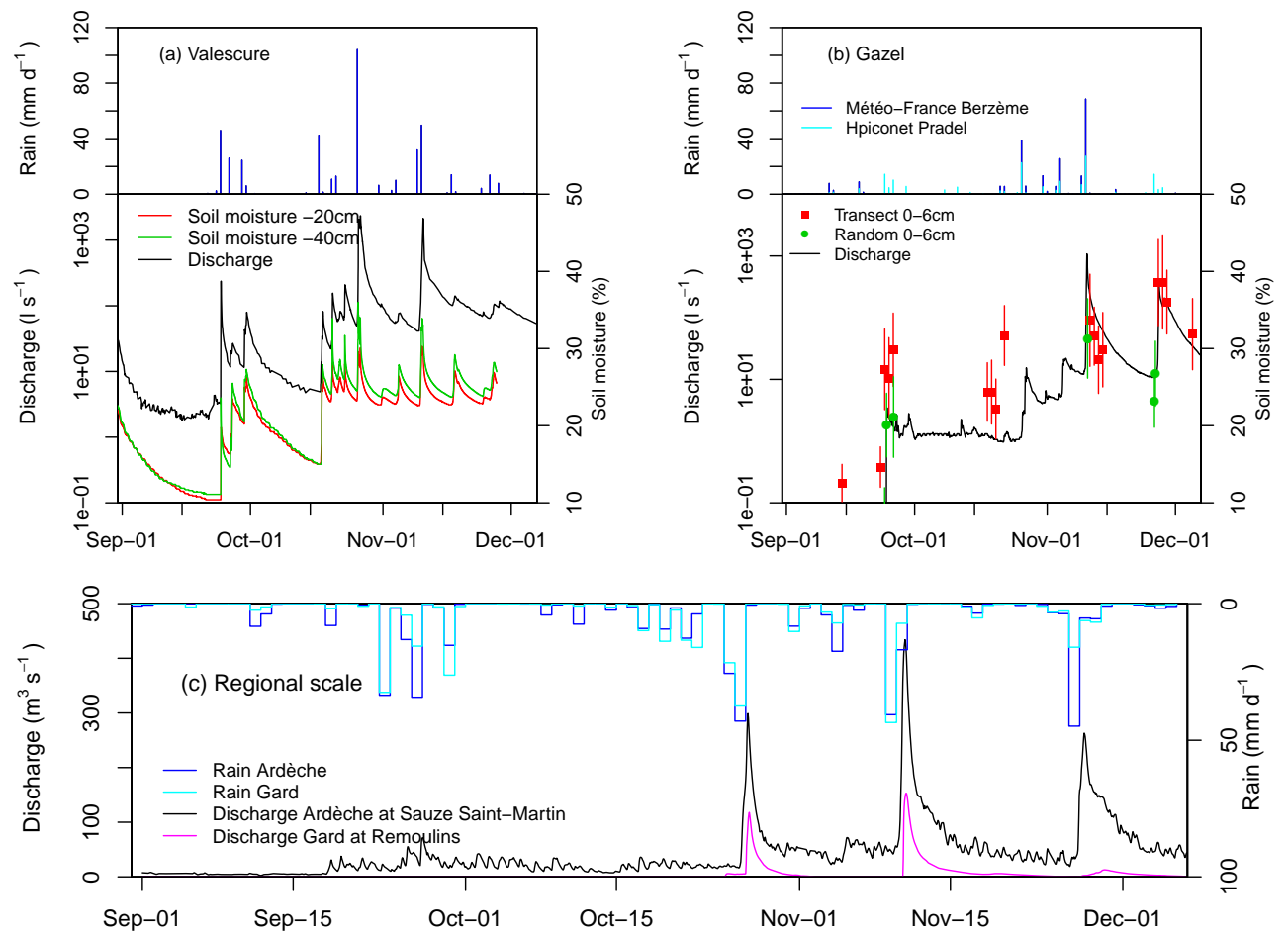

Figure 9. (a) Daily rainfall at the Castle spring rain gauge in the Valescure catchment (top panel); variable time step discharge (black) and local soil water content at 20 (red) and 40 (green) cm depths in one site of Transect T2 in the Valescure catchment during autumn 2012 (see Fig. 4a for the location of T2 and the Castle spring). (b) Daily rainfall at two stations Berzème and Le Pradel (top panel); hourly discharge (black) and manual soil moisture performed along six transects (red) or randomly (green) in the Gazel catchment. (c) Average daily catchment rainfall from the SAFRAN-ISBA-MODCOU reanalysis for the Ardèche and Gard catchments (top) and corresponding hourly discharge at the catchments outlets.

dry during September and remain dry on 25 October, without significant discharge at their outlets (Fig. 9c). The 26 October event significantly wets the soils in the upper part of the catchments (Fig. 10d), but the downstream part remains unsaturated, with lower values of the SWI in the Gard. A quick discharge increase is observed at both outlets after this event (Fig. 9c). The response is larger for the Ardèche catchment than for the Gard, associated with a higher SWI. The subsequent events, and especially the 9-10 November event (Fig. 10e), lead to full saturation of the two catchments. The soils remain saturated during the whole month of November (Fig. 10f). The catchment response to the last two events is very quick. As for the Valescure and Gazel catchments, the response to the 9-10 November event is larger, although the rainfall amount is lower or similar: 68.5 (63.1) $\mathrm{mm}$ for the 25-26 October event and 67.5 (50.7) $\mathrm{mm}$ for the 9-10 November events in the Ardèche (the Gard) catchments. Nevertheless, low maximum peak discharges are recorded: for instance only $434 \mathrm{~m}^{3} \mathrm{~s}^{-1}$, i.e. $10 \%$ of the maximum ever recorded at the outlet of the Ardèche catchment (maximum peak discharge recorded in the Ardèche at Sauze St-Martin about $4500 \mathrm{~m}^{3} \mathrm{~s}^{-1}$, and maximum daily discharge $2510 \mathrm{~m}^{3} \mathrm{~s}^{-1}$ ).
Figures 9 and 10 show that, on the three scales (local, small catchment, regional scale), similar behaviours are observed with a progressive wetting of the catchments during the SOP, until saturated conditions are reached after 27 October in the Valescure catchment and 9-10 November in the Gazel and on a regional scale. Once saturated conditions are reached, the response in terms of discharge is quicker and larger, even if the rainfall amounts are not so important. There is therefore a high consistency of the relationship between soil moisture variations and catchment response on the three scales. Our study catchments were not affected by very high rainfall events in 2012, so the observations conducted in the autumn in the next few years will provide more data to confirm whether the results obtained in 2012 can be generalized.

\subsection{What are the active hydrological processes on different spatial and temporal scales during the 9-11 November 2012 event?}

In this section, we illustrate how the data collected on the various spatial scales can be used to derive information about active processes during the rainfall event which occurred on 9-11 November 2012. The rainfall amount was $93 \mathrm{~mm}$ in the Valescure catchment and $100 \mathrm{~mm}$ in 


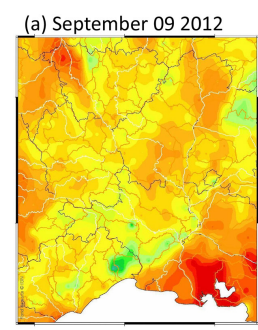

(d) October 312012
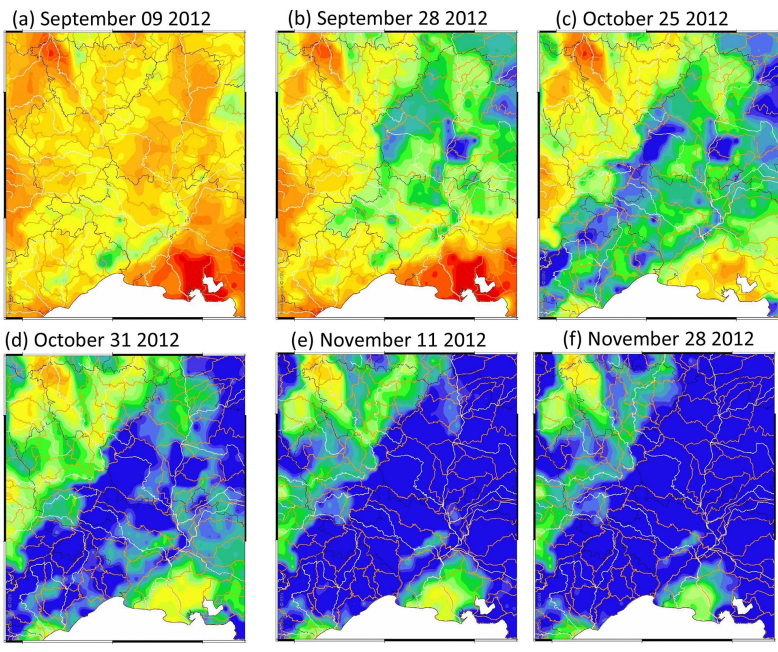

Figure 10. Maps of the soil wetness index (SWI) derived from the SAFRAN-ISBA-MODCOU chain for six dates during autumn 2012. An SWI of 0 means dry soils and an SWI of 1 saturated soils. Catchments boundaries appear in brown and main rivers in white.

the Tourgueille catchment, and the rainfall recorded in the Claduègne catchment varied between $63 \mathrm{~mm}$ (Le Pradel) and $82 \mathrm{~mm}$ (Berzème) (see also Fig. 9). For this event, we examine the results provided by the geochemistry sampling in the Valescure catchment, the limnimeters networks (Valescure and Claduègne catchments), as well as the discharge response on all scales.

Figure 11 shows the simultaneous behaviour of the electrical conductivity (EC), isotopic composition $\delta^{18} \mathrm{O}, \mathrm{Ca}, \mathrm{Al}$ and TOC concentration of the stream water in the Valescure catchment $\left(3.9 \mathrm{~km}^{2}\right)$ during the 9-10 November 2012 flood event. Note that because of sensor failure, discharge at the outlet had to be reconstructed from the data at the other gauging stations: the discharge of the four upstream sub-catchments has been summated after a translation using a constant velocity of $2 \mathrm{~m} \mathrm{~s}^{-1}$. For the downstream subcatchment, a rainfall-runoff model, previously calibrated on the catchment, has been used. The increase of TOC, Al, the dilution of $\mathrm{Ca}$ and the variation of EC correspond in time with the discharges. About ${ }^{18} \mathrm{O}$, there is also a good synchronization with the discharges at the beginning of the flood, till 00:00 UTC on 10-11 November, but the isotopic composition then appears to be independent from the discharge. This is due to the fact that the isotopic composition of the rainfall changes between 09:00 and 10:00 UTC, from nearly -2.5 to $-5 \%$. This latter value is very close to the one of the stream a few hours later, so that variations cannot be detected anymore after this moment. The runoff decomposition between "old" water (i.e. pre-existing water) and "new" water (i.e. rainfall water) is based on the assumption that the stream water is a mixing between (1) rainwater and (2) the isotopically and chemically constant base flow constituted of deep water (groundwater and/or weathered area water) determined

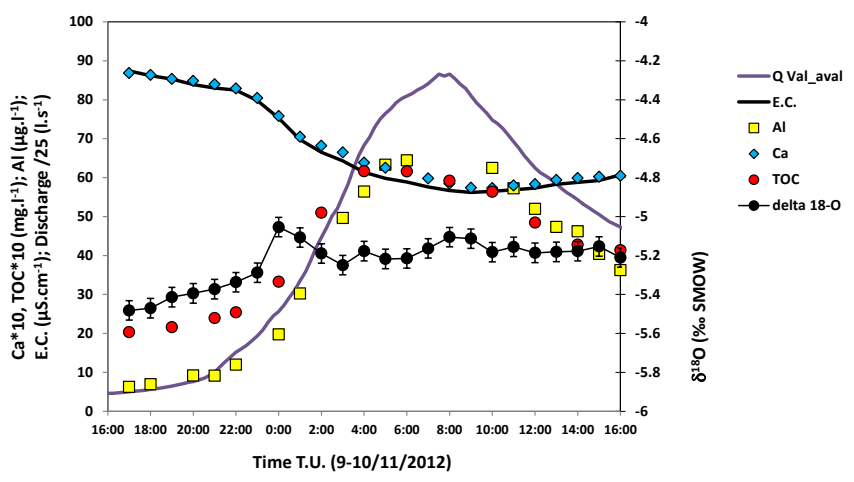

Figure 11. Left: time evolution of the Valescure stream water electrical conductivity $(\mathrm{EC})$, Calcium $(\mathrm{Ca})$, Aluminum (Al), total organic carbon (TOC) and Cartaou subsystem discharge during the 9-10 November 2012 flood. Right: Valescure stream water isotopic composition $\left(\delta^{18} \mathrm{O}\right)$.

at the onset of the event. By using $\mathrm{EC}$ and $\mathrm{Ca}$, new water $\left(\mathrm{EC}=28 \mu \mathrm{S} \mathrm{cm}^{-1}, \mathrm{Ca}=0.8 \mathrm{mg} \mathrm{L}^{-1}\right)$ is found to be between 36 and $56 \%$ of the runoff at the peak. For another event (2627 October 2012), $\delta^{18} \mathrm{O}$ led to a $35 \%$ contribution of new water at peak flow. Terrigenous elements such as $\mathrm{Al}$ and TOC could also help assess the contribution of the different layers of the soil to the flood. This first result must be refined by:

1. accounting for the soil water isotopic or chemical composition, which is now monitored before the beginning of each event;

2. applying a three-component mixing, including rainfall water, soil water and deep water;

3. considering a larger range of events to relate the contribution to the magnitude of the floods;

4. relating both the old and new water proportions to the understanding of the real processes of both surface and sub-surface flow.

This will be achieved by combining geochemical data with physically based hydrodynamical models. Note also that it is expected that a flood of major magnitude would bring different contributions in surface or sub-surface water flows at the outlet of the catchment. This information will be used for calibrating the hydrological processes with multi-variable controls, such as discharges, of course, but also geochemistry.

For the same event, Fig. 12 shows the river network extension 4 days before, during and 9 days after the event, as obtained from the limnimeters network and field survey in the Cartaou catchment (Valescure sub-catchment). The maximum extent of the active hydrographic network observed on 10 November 2012 is quite comparable to those of the first two episodes of the autumn (24 September and 26 October not shown). We note a significant extension of the active network before (Fig. 12a) the event. The extension is at a maximum during the event (Fig. 12b) and decreases after the event 

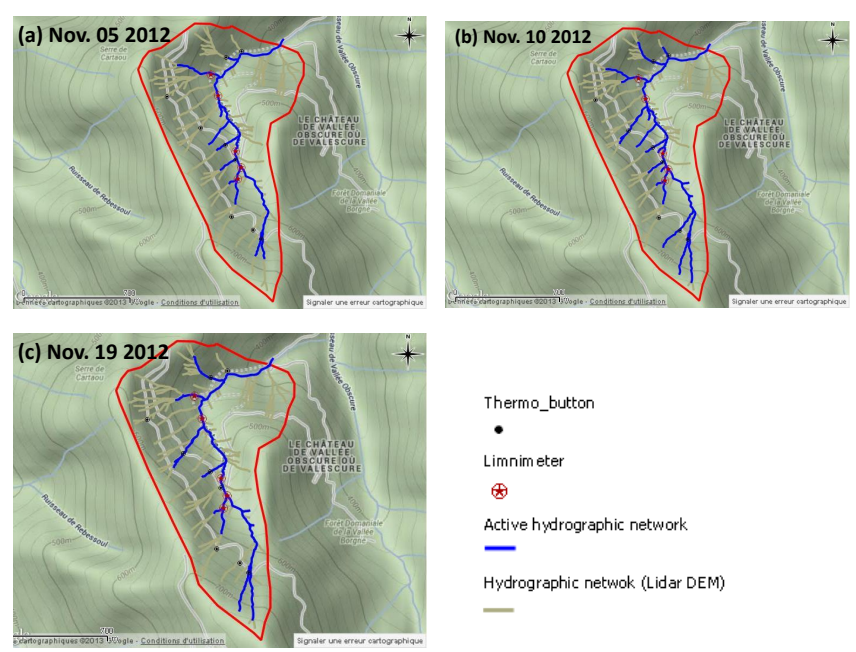

Figure 12. Mapping of the active hydrographic network within the Cartaou sub-catchment 4 days before (a), during (b) and 9 days (c) after the 9-10 November 2012 event. Stars show the location of the limnimeters and the black points those of the thermo-buttons. The blue lines show the active hydrographic network at the various dates and the brown lines the "potential" river network as derived from a $1 \mathrm{~m}$ resolution lidar DEM analysis.

(Fig. 12c). The significant extension of the active network before and after the 10-11 November event is consistent with the high soil moisture level (about 30\%) which is reached after the 26 October event and remains high after that (see Fig. 9a).

Figure 13 shows the limnimeter response to the same event for the Claduègne catchment. The rainfall presents a slight altitudinal gradient with more rainfall at higher altitude, but a good synchronization in the intensities. The catchment was probably not fully saturated at the beginning of the event, as shown by the absence of reactions to the first rainfall peak at points $\mathrm{sg} 1, \mathrm{mi} 4$ and $\mathrm{sj} 3$, which only respond to the second peak (Fig. 13c-e). Some points react very quickly to rainfall such as $\mathrm{sj} 2$, which corresponds to badlands and is prone to Horton runoff (Fig. 13e), and to a lesser extent bz1 on basaltic scoria (Fig. 13c). Some limnimeters do not react at all (e.g. sg2, Fig. 13e). The response appears quite differentiated according to the lithology and possibly land use. In terms of scale, the response is quite similar and synchronous for the three largest catchments (Fig. 13b), explained by high velocity in the river network $\left(2-2.5 \mathrm{~m} \mathrm{~s}^{-1}\right.$ measured at the Claduègne outlet around the peak), but with longer recessions for the largest catchments. The analysis of more events will be necessary to confirm the role of lithology and/or land use on the sub-catchment characteristics.

Figure 14a provides the cumulative rainfall for the event duration (9-10 November) using an ordinary kriging of the rainfall gauges. Although smoothed as compared to radar data, it illustrates the large spatial variability of the cumulative rainfall amount on the regional scale. The response in terms of specific discharges is quite different across scales in the Ardèche (Fig. 14b) and Gard (Fig. 14c) catchments. In the Gard, the maximum peak discharge decreases with increasing catchment size, which also reflects the lower cumulative rainfall amount, when moving downstream. In the Ardèche catchment, the maximum specific peak discharge is of the same order of magnitude for a large range of catchments sizes (from 3.4 to about $600 \mathrm{~km}^{2}$ with the exception of catchment no. 3). There is a link between maximum specific peak discharge and the cumulative rainfall (e.g. in the smallest catchments, nos. 1, 2 and 11) but also no. 4 which has been affected by a large cell with cumulative rainfall larger than $90-105 \mathrm{~mm}$. The picture is certainly more complex, requiring further analysis, in particular by considering the impact of rainfall intensity, which will be possible when accurate radar rainfall estimates are available.

The first results presented in this section show that, for the selected event, sub-surface flow processes, initial soil moisture as well as lithology are important factors explaining the hydrological response on small scales. Rainfall variability becomes an important factor when moving to larger scales. Given the moderate peak discharge registered for this event, it cannot be considered as a flash flood event, but provides interesting insight into the hydrological response under moderate rainfall conditions. The analysis of other events and of the continuous time series will help gain more insight into the interplay of the various factors of the hydrological response and into the identification of possible specific responses during flash flood events.

\subsection{How efficient are the methods proposed in the study in quantifying and reducing rainfall and discharge uncertainty?}

Figure 15 gives an example of hourly estimates together with their uncertainty obtained by the reanalysis methodology laid out in Delrieu et al. (2014b). In this example, the estimation is performed for hydrological meshes of $10 \mathrm{~km}^{2}$ over the four main Cévennes watersheds (Ardèche, Cèze, Gardons, Vidourle). The top graphs display the estimates obtained by the rain gauge network through ordinary kriging alone (left) and with the radar-rain-gauge merging through kriging with external drift (right). In the bottom graphs, the corresponding maps of standard deviations of the estimation error are displayed with much smaller values for the KED estimates, indicative of the added value of the radar data for the considered time- and space scales. These results are very promising and will be used to improve the rainfall field estimates, especially during HyMeX EOP, where additional research radars are available. As mentioned in Sect. 2.3, these additional radars will be very useful in improving our knowledge of rainfall spatial and temporal variability for catchments of about $1-100 \mathrm{~km}^{2}$. 

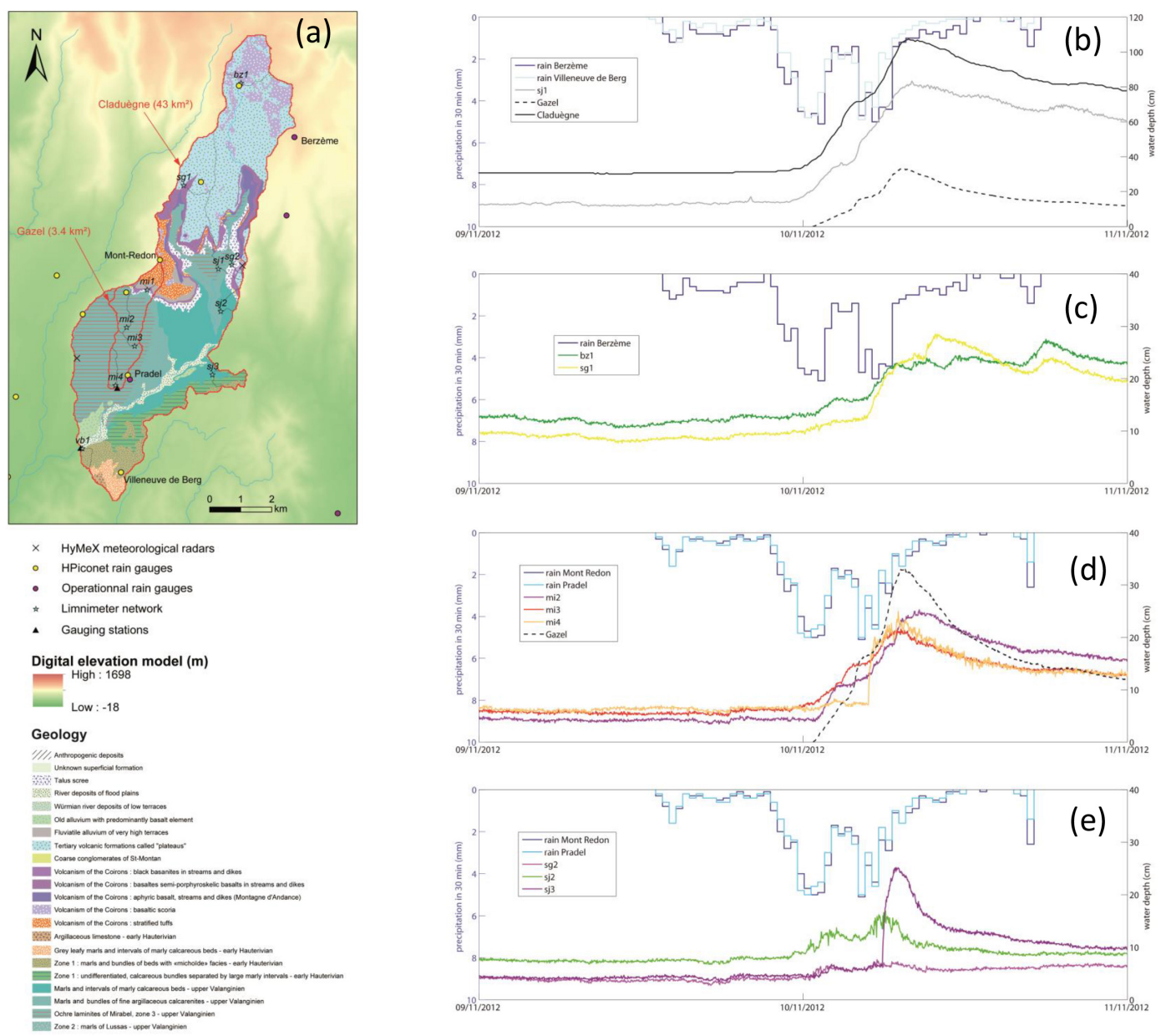

Figure 13. Water level from the limnimeters network of the Claduègne catchment for the 9-11 November 2012 event. The location of the various limnimeters is shown in panel (a), which also provides the geology map from BRGM (Bureau de Recherches Géologiques et Minières). On the right, the various panels present several groups of limnimeters and the associated representative rain gauges: (a) the three largest sub-catchments: Gazel, sj1, Claduègne (3.4, 12.3, $43 \mathrm{~km}^{2}$ respectively); (b) two headwater sub-catchments bz1 and sg1 on basalt geology; (c) four sub-catchments in the Gazel: mi2 and mi4 on marl-calcareous geology, mi3 and Gazel with a mix of marl-calcareous and basalt geology; (d) three sub-catchments with different geologies: sj2 with regosols, sj3 with marls and sg2 with basalt and forest.

Figure 16 illustrates how the additional stream gauging from the opportunistic measurements or from the continuous LSPIV system can improve the stage-discharge relationship accuracy for the Volane River, a tributary of the upper Ardèche River (no. 4 in Fig. 14a). The stage-discharge relationship itself is not very sensitive to the additional gaugings (all the four curves are superimposed in Fig. 16), because the station section is very stable and well controlled. The impact of new gaugings is very visible on the corresponding uncertainty. For instance, at $1.5 \mathrm{~m}$ the uncertainty is $49 \%$ when only standard gaugings (black points) are considered (grey shading). Although the LS-PIV gaugings (red points) from year 2012 only sampled moderate discharges, their addition to the analysis reduces the uncertainty to $35 \%$ at $1.5 \mathrm{~m}$ (pink shading). In October 2013, one very intense event hit this catchment, with a maximum water height of $2.6 \mathrm{~m}$, far beyond the maximum ever gauged. Three SVR opportunistic measurements (blue points) were performed around $1.5 \mathrm{~m}$. When these gauging are combined with the standard gaugings, the uncertainty at $1.5 \mathrm{~m}$ (blue shading) is $45 \%$. So although they have a larger error than the SVR gaugings, the numerous LS-PIV gaugings at moderate discharge decrease the uncertainty more than the three SVR gaugings at high discharge. When all the gaugings are used in the analysis (green shading), the uncertainty at $1.5 \mathrm{~m}$ is reduced to $29 \%$, showing the added value of the two types of non-contact gaugings. This kind of analysis will be performed for the other gauging stations and used to quantify the uncertainty of the discharge time series and hydrological water balance, which can be used in the evaluation of the hydrological models.

The results presented in this section illustrate the value of the proposed methods in quantifying and reducing the uncertainty of both rainfall fields and discharge time series for flash flood studies. 


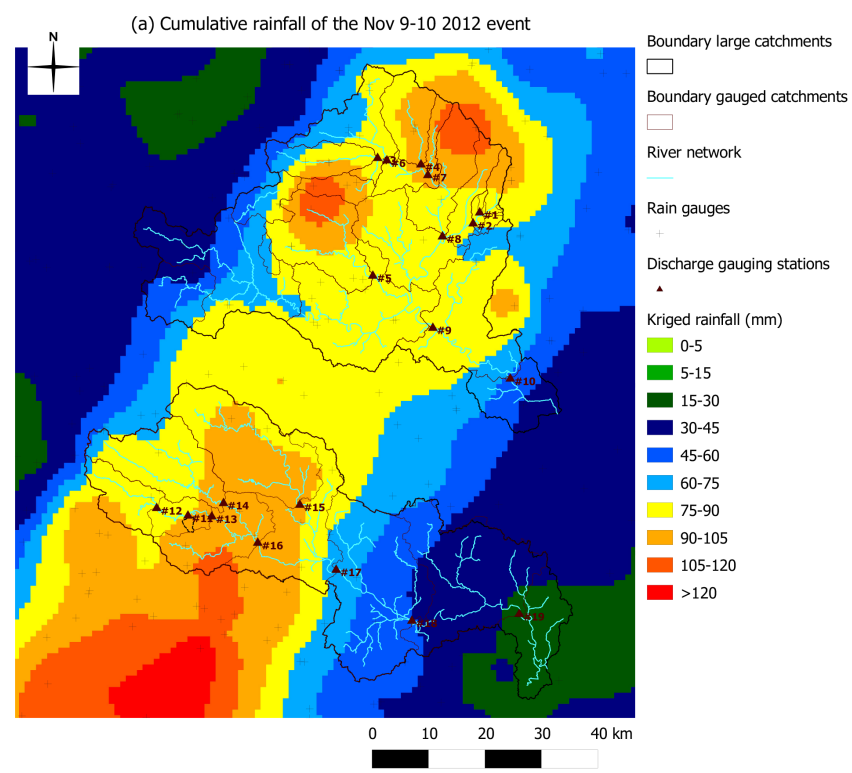

(a) OK: estimation

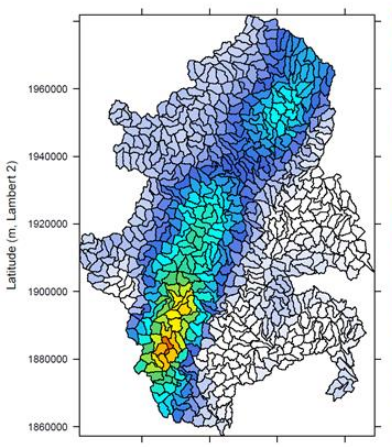

(c) OK: error STD

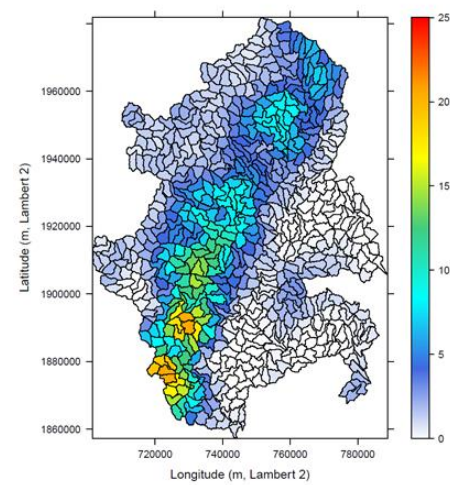

(b) KED: estimation

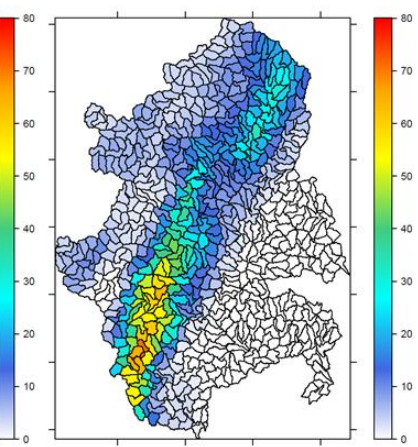

(d) KED: error STD

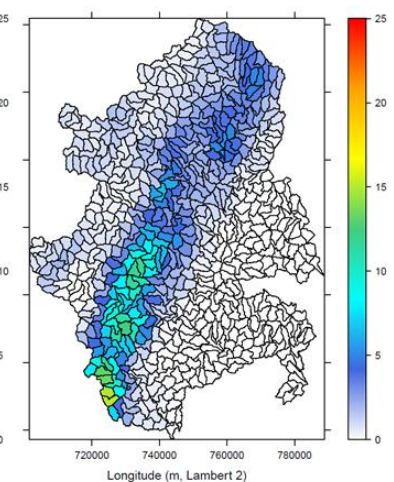

Figure 15. Ordinary kriging estimates from the rain gauge network (left) and kriging with external drift estimates from radarrain-gauge merging (right) for the 21 October 2008 between 21:00 and 22:00 UTC. The top graphs display the hourly rain amounts $(\mathrm{mm})$ and the bottom graphs the corresponding error standard deviations $(\mathrm{mm})$. The results are provided for a hydrological mesh of $10 \mathrm{~km}^{2}$.

the historical records, which can provide useful information about catchment characteristics or functioning (see the recent review of Troch et al., 2013).

The iterative approach is illustrated using the CVN noncalibrated model, described in Sect. 3. First simulations, based on soil storage capacity derived from available soil databases, which only describe the topsoil relevant for agronomic purposes, lead to poor simulation results, as illustrated in Fig. 17 for the Ardèche at the Meyras catchment (no. 3 in Fig. 14a). The model simulation is too responsive, with an overestimation of peak discharges and recessions that are too quick. The specification of the water storage capacity of the soil is therefore re-examined, using new data analysis (recession analysis) of available long-term discharge series. The objective is to estimate catchment storage capacity and saturated hydraulic conductivity in the weathered bedrock, which are not documented in the existing soil databases. Weathered bedrock has been shown to be a significant source of water storage within the studied catchments (Vannier et al., 2013). Geology is identified as the main driver governing the 


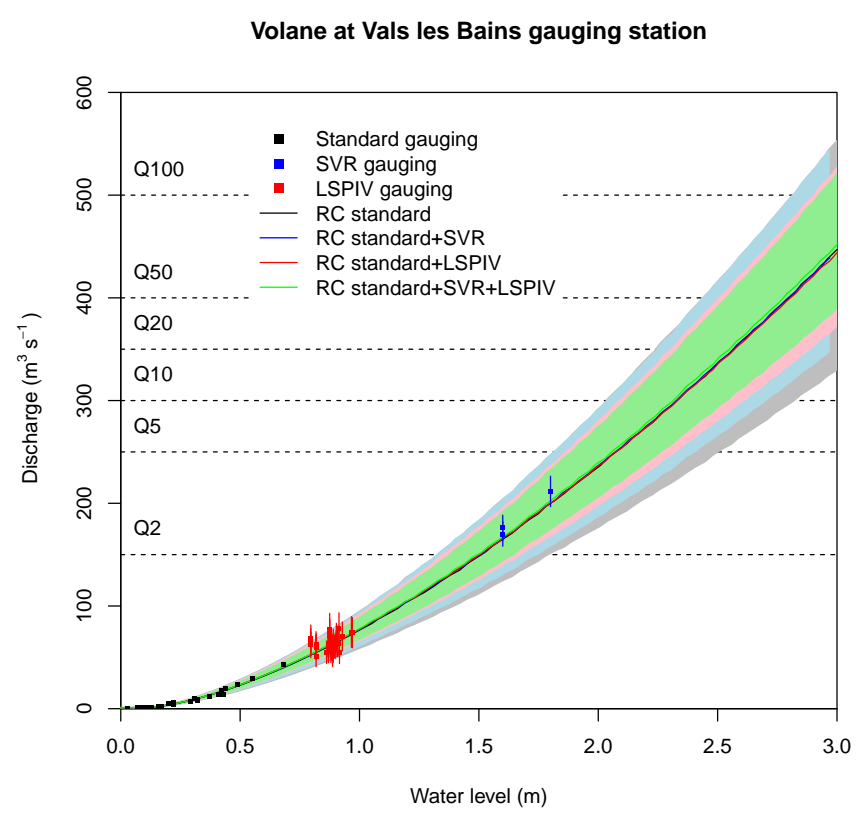

Figure 16. Illustration of the error reduction in discharge estimation when opportunistic SVR measurements (blue points) and LS-PIV (red points) stream gaugings for high flow are added to standard gaugings (black points) in the stage-discharge estimation. The error bars correspond to errors of $5 \%$ for standard gaugings, $7 \%$ for SVR gaugings and $20 \%$ for LS-PIV gaugings. The lines are the rating curve (RC) computed using the BaRatin software, and the shaded colours correspond to the $95 \%$ uncertainty bounds when standard gaugings only (grey), standard + SVR (blue), standard + LS-PIV (red) and standard + SVR + LS-PIV (green) gaugings are included in the RC computation.

range of these characteristics (Vannier et al., 2013). Figure 17 shows that the use of this information into the CVN model improves both the long-term and event discharge simulation, even if the peaks are still overestimated and the recessions are still too quick. The improvement is very significant when the underlying geology is granite (Vannier, 2013). The simulation results are still improved when the weathered layer is included for schist geology, but the recessions remain too quick (not shown, see Vannier, 2013).

The CVN model is based on the bottom-up modelling approach. The data-driven method (or top-down approach) is also used to see how they, i.e. the top-down and the bottomup approaches, can be complementary. The Kirchner (2009) method is applied to the recession analysis of natural discharge time series of the Ardèche catchment (Adamovic et al., 2014), leading to a simple model of catchment functioning where the discharge at the outlet is assumed to depend only on the catchment storage, and where the parameters of the model are estimated from the data. The method performs much better for catchments with granite geology (Adamovic et al., 2014). The results also show that, in winter, such catchments can be considered as simple dynamical systems and that discharge fluctuations can be assumed to
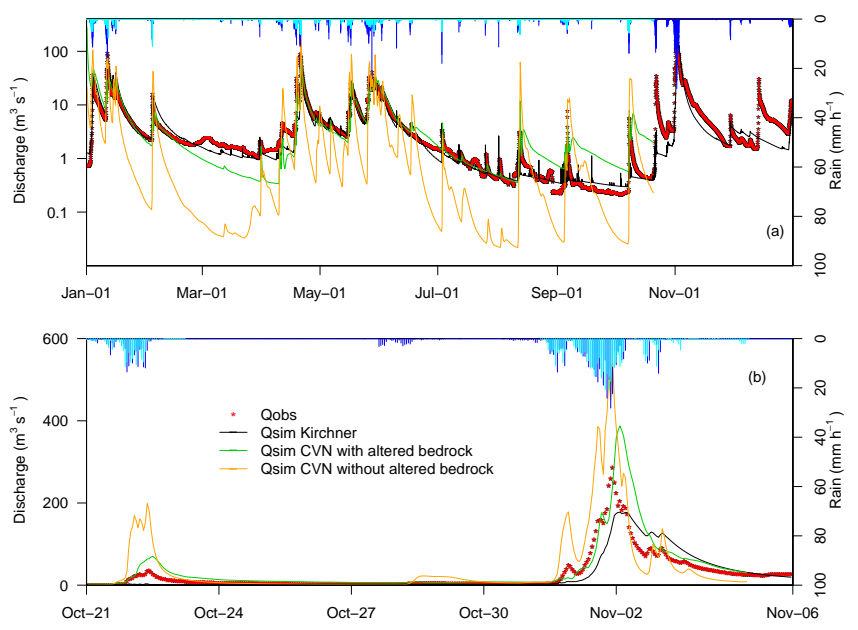

Figure 17. Simulated and observed discharge (red points) from 1 January to 31 December 2008 for the Ardèche at the Meyras gauging station $\left(98 \mathrm{~km}^{2}\right)$. The simulations correspond to the CVN model with and without taking into account the altered bedrock layer (green and orange respectively) and the model based on the Kirchner (2009) modelling approach (black). This graph is provided in log scale for the discharge in panel (a) for the year 2008, and the rainfall corresponds to an hourly local gauge (dark blue) and SAFRAN-ISBA-MODCOU reanalysis (light blue). Panel (b) provides a zoom (in linear scale) for the period 20 October-6 November 2008 with two significant events. The rainfall corresponds to an hourly local gauge (dark blue) and hourly kriged estimates (light blue).

be mainly governed by change in catchment water storage. However, the results are much poorer during the summer periods where evapotranspiration influence adds complexity to the catchment response (Fig. 17). Figure 17 also shows that both modelling approaches provide quite good results during wet periods. Recessions are somewhat better simulated with the Kirchner method, but the peak of the November 2008 event has a delay as compared to observation. On the other hand, the timing of the CVN model is more in agreement with the data.

These results illustrate how the iterative approach of Fig. 2 helps enhance our knowledge of the functioning of the catchments on a regional scale and of ungauged catchments in an incremental manner. The combined use of the top-down and bottom-up approach is also promising, and the next step will be the generalization of comparisons such as the one of Fig. 17. The new data collected thanks to the experimental set-up presented in Sect. 2 will provide new times series on different scales, which will be analysed following the same approaches in order to confirm or disprove and generalize the conclusions drawn from the analysis of historical discharge time series, for instance the importance of geology on the differentiation of the hydrological response in the study area. 


\section{Conclusions and perspectives}

To conclude we hope that the first results presented above demonstrate that the proposed multi-scale approach, combining observation and modelling, will allow significant progresses in flash flood understanding and therefore predictability due to the following characteristics:

1. the duration of the observations (4 years), which allows the characterization of the standard catchment behaviour and therefore the characterization of exceptional processes which have not yet been observed and are specific to flash floods;

2. the regional spatial coverage of the experimental set-up (two large catchments of more than $2000 \mathrm{~km}^{2}$ ) and the variability of geology, land uses and soil types which are sampled on a small scale that allows an adequate sampling of the variability of responses;

3. a significant effort dedicated to the documentation of the soil water storage which has been shown to be able to explain exceptional behaviours (see for instance Rogger et al., 2012);

4. the variety of scales and of instrumental techniques (continuous, opportunistic, VHR imagery, etc.) deployed in two regional catchments, which allows the simultaneous documentation of various aspects of the hydrological response;

5. the high resolution of the acquired rainfall fields and the provision of the associated errors bars, as well as the use of the stochastic rainfall generator that will allow interesting sensitivity analyses of the hydrological response to the rainfall variability.

The data collection and analysis is still ongoing. The SOP1 in autumn 2012 was not rich in exceptional events in our study area, but it allowed testing the sensors, and of the opportunistic protocols, so that we are ready for the autumn of the next few years. The 4-year duration of the experiment will allow the collection of a rich data set on hydrological processes during and between flash floods using both continuous and opportunistic observations on various scales. As illustrated in Fig. 2, the combined analysis of observation and simulations in a "hypothesis testing framework" will allow the comparison of different hypotheses about active processes in order to better understand the dominant processes during and between floods as well as the impact of differences in landscape characteristics.

As a concluding remark we would like to underline that, although focused on Mediterranean catchments, the multiscale observation strategy of Fig. 1 and the iterative approach presented in Fig. 2 can be generalized and adapted to other hydro-climatic contexts.
Acknowledgements. The FloodScale project is funded by the French National Research Agency (ANR) under contract no. ANR 2011 BS56 027, which contributes to the HyMeX program. It also benefits from funding by the MISTRALS/HyMeX program (http://www.mistrals-home.org). The OHM-CV is an observation service certified in 2006 and funded by the Institut National des Sciences de l'Univers/Surface et Interfaces Continentales. The Ph.D. theses of M. Adamovic and A. Wijbrans are funded by Region Rhône-Alpes. The authors acknowledge CNES for providing the Pléiades images and data processing through a TOSCA program project, Météo-France for providing rainfall data, SCHAPI for providing discharge data and Alexandre Hauet for his help in getting the EDF-DTG discharge data. Sandra Perez from UMR ESPACE contributed to the building of the FloodScale project. The authors thank Stanislas Bonnet, Louise Jeandet, Mickaël Lagouy, Florent Le Floch and Mélissa Vuarant for their participation in the field infiltration tests and deployment of the saturometer in the Claduègne catchment; Martin Caliano for his help in the SOP1 field survey, Isabella Zin and Jeremy Chardon for providing the analog rainfall forecasting and Gilles Molinié for his investment in the HPiconet network. The additional radars deployed during SOPs 2012 and 2013 were provided by EPFL, LaMP, NSSL/NOAA and NOA. The HyMeX database teams (ESPRI/IPSL and SEDOO/Observatoire Midi-Pyrénées) helped in accessing the data. We also thank D. Archer and one anonymous reviewer for their valuable comments, which helped improve the quality of the paper.

Edited by: H. Cloke

\section{References}

Adamovic, M., Branger, F., Braud, I., and Kirchner, J.: Does the Kirchner discharge recession analysis provide useful information about catchment hydrological functioning in a Mediterranean context? Application to the Ardèche catchment (France), Hydrol. Earth Syst. Sci., in preparation, 2014.

Ali, G., Tetzlaff, D., Soulsby, C., and McDonnell, J. J.: Topographic, pedologic and climatic interactions influencing streamflow generation at multiple catchment scales, Hydrol. Process., 26, 3858$3874,2012 \mathrm{a}$

Ali, G., Tetzlaff, D., Soulsby, C., McDonnell, J. J., and Capell, R.: A comparison of similarity indices for catchment classification using a cross-regional dataset, Adv. Water Resour., 40, 11-22, 2012b.

Ali, G. A., Roy, A. G., Turmel, M.-C., and Courchesne, F.: Multivariate analysis as a tool to infer hydrologic response types and controlling variables in a humid temperate catchment, Hydrol. Process., 24, 2912-2923, 2010.

Ambroise, B.: Variable "active" versus "contributing" areas or periods: a necessary distinction, Hydrol. Process., 18, 1149-1155, 2004.

Anderson, A. E., Weiler, M., Alila, Y., and Hudson, R. O.: Dye staining and excavation of a lateral preferential flow network, Hydrol. Earth Syst. Sci., 13, 935-944, doi:10.5194/hess-13-9352009, 2009.

Anquetin, S., Braud, I., Vannier, O., Viallet, P., Boudevillain, B., Creutin, J.-D., and Manus, C.: Sensitivity of the hydrological 
response to the variability of rainfall fields and soils for the Gard 2002 flash-flood event, J. Hydrol., 394, 134-147, 2010.

Beighley, R., Dunne, T., and Melack, J.: Understanding and modelling basin hydrology: interpreting the hydrological signature, Hydrol. Process., 19, 1333-1353, 2005.

Birkinshaw, S. J. and Webb, B.: Flow pathways in the Slapton Wood catchment using temperature as a tracer, J. Hydrol., 383, 269279, 2010.

Blöschl, G.: Hydrologic synthesis: accross processes, places and scales, Water Resour. Res., 42, W03S02, doi:10.1029/2005WR004319, 2006.

Blöschl, G. and Sivapalan, M.: Scales issues in hydrological modeling - a review, Hydrol. Process., 9, 251-290, 1995.

Blöschl, G. and Zehe, E.: On hydrological predictability, Hydrol. Process., 19, 3923-3929, 2005.

Bonnifait, L., Delrieu, G., Lay, M. L., Boudevillain, B., Masson, A., Belleudy, P., Gaume, E., and Saulnier, G.-M.: Distributed hydrologic and hydraulic modelling with radar rainfall input: Reconstruction of the 8-9 September 2002 catastrophic flood event in the Gard region, France, Adv. Water Resour., 32, 1077-1089, 2009.

Borga, M., Boscolo, P., Zanon, F., and Sangati, M.: Hydrometeorological Analysis of the 29 August 2003 Flash Flood in the Eastern Italian Alps, J. Hydrometeorol., 8, 1049-1067, 2007.

Borga, M., Gaume, E., Creutin, J., and Marchi, L.: Surveying flash floods: gauging the ungauged extremes, Hydrol. Process., 22, 3883-3885, 2008.

Borga, M., Anagnostou, E. N., Blöschl, G., and Creutin, J. D.: Flash floods: Observations and analysis of hydro-meteorological controls, J. Hydrol., 394, 1-3, 2010.

Borga, M., Anagnostou, E. N., Blöschl, G., and Creutin, J. D.: Flash flood forecasting, warning and risk management: the HYDRATE project, Environmental Science Policy, 14, 834-844, 2011.

Boudevillain, B., Delrieu, G., Galabertier, B., Bonnifait, L., Bouilloud, L., Kirstetter, P.-E., and Mosini, M.-L.: The Cevennes-Vivarais Mediterranean Hydrometeorological Observatory database, Water Resour. Res., 47, W07701, doi:10.1029/2010WR010353, 2011.

Bouilloud, L., Delrieu, G., Boudevillain, B., and Kirstetter, P. E.: Radar rainfall estimation in the context of post-event analysis of flash-flood events, J. Hydrol., 394, 17-27, 2010.

Boulier, J.-F., Parlange, J.-Y., Vauclin, M., Lockington, D. A., and Haverkamp, R.: Upper and lower bounds of the ponding time for near constant surface flux, Soil Sci. Soc. Am. J., 51, 1424-1428, 1987.

Bracken, L. J. and Croke, J.: The concept of hydrological connectivity and its contribution to understanding runoff-dominated geomorphic systems, Hydrol. Process., 21, 1749-1763, 2007.

Branger, F., Braud, I., Debionne, S., Viallet, P., Dehotin, J., Hénine, H., Nédélec, Y., and Anquetin, S.: Towards multi-scale integrated hydrological models using the LIQUID framework. Overview of the concepts and first application examples, Environ. Modell. Softw., 25, 1672-1681, 2010.

Brath, A. and Montanari, A.: The effects of the spatial variability of soil infiltration capacity in distributed flood modelling, Hydrol. Process., 14, 2779-2794, 2000.

Braud, I., Vich, A., Zuluaga, J., Fornero, L., and Pedrani, A.: Vegetation influence on runoff and sediment yield in the Andes region: observation and modelling, J. Hydrol., 254, 124-144, 2001.
Braud, I., Roux, H., Anquetin, S., Maubourguet, M.-M., Manus, C., Viallet, P., and Dartus, D.: The use of distributed hydrological models for the Gard 2002 flash flood event: Analysis of associated hydrological processes, J. Hydrol., 394, 162-181, 2010.

Braud, I. et al.: Interactive comment on "Multi-scale hydrometeorological observation and modelling for flash-flood understanding" by I. Braud et al., Hydrol. Earth Syst. Sci. Discuss., 11, C811C811, 2014a.

Braud, I. et al.: Interactive comment on "Multi-scale hydrometeorological observation and modelling for flash-flood understanding" by I. Braud et al., Hydrol. Earth Syst. Sci. Discuss., 11, C1117C1117, 2014b.

Brunet, P., Clément, R., and Bouvier, C.: Monitoring soil water content and deficit using Electrical Resistivity Tomography (ERT) a case study in the Cevennes area, France, J. Hydrol., 380, 146153, 2010.

Burke, A. R. and Kasahara, T.: Subsurface lateral flow generation in aspen and coniferdominated hillslopes of a first order catchment in northern Utah, Hydrol. Process., 25, 1407-1417, 2011.

Buttle, J. and McDonald, D.: Coupled vertical and lateral preferential flow on a forested slope, Water Resour. Res., 38, 1060, doi:10.1029/2001WR000773, 2002.

Casper, M., Volkmann, H., Waldenmeyer, G., and Plate, E.: The separation of flow pathways in a sandstone catchment of the NorNorth Black Forest using DOC and a nested approach, Phys. Chem. Earth, 28, 269-275, 2003.

Cerdan, O., Le Bissonnais, Y., Govers, G., Lecomte, V., van Oost, K., Couturier, A., King, C., and Dubreuil, N.: Scale effect on runoff from experimental plots to catchments in agricultural areas in Normandy, J. Hydrol., 299, 4-14, 2004.

Clark, M., Kavetski, D., and Fenicia, F.: Pursuing the method of multiple working hypotheses for hydrological modeling, Water Resour. Res., 47, W09301, doi:10.1029/2010WR009827, 2011.

Coopersmith, E., Yaeger, M. A., Ye, S., Cheng, L., and Sivapalan, M.: Exploring the physical controls of regional patterns of flow duration curves - Part 3: A catchment classification system based on regime curve indicators, Hydrol. Earth Syst. Sci., 16, $4467-$ 4482, doi:10.5194/hess-16-4467-2012, 2012.

Cosandey, C. and Didon-Lescot, J.: Etude des crues cévenoles: conditions d'apparition dans un petit bassin forestier sur le versant sud du Mont Lozère, France, in: Regionalisation in Hydrology, IAHS Publication, Ljubljana, Slovenia, 191, 103-115, 1990 (in French).

Coustau, M., Bouvier, C., Borrell-Estupina, V., and Jourde, H.: Flood modelling with a distributed event-based parsimonious rainfall-runoff model: case of the karstic Lez river catchment, Nat. Hazards Earth Syst. Sci., 12, 1119-1133, doi:10.5194/nhess-12-1119-2012, 2012.

Creutin, J. D. and Borga, M.: Radar hydrology modifies the monitoring of flash-flood hazard, Hydrol. Process., 17, 1453-1456, 2003.

Dehotin, J. and Braud, I.: Which spatial discretization for distributed hydrological models? Proposition of a methodology and illustration for medium to large-scale catchments, Hydrol. Earth Syst. Sci., 12, 769-796, doi:10.5194/hess-12-769-2008, 2008.

Delrieu, G., Ducrocq, V., Gaume, E., Nicol, J., Payrastre, O., Yates, E., Kistetter, P., Andrieu, H., Ayral, P., Bouvier, C., Creutin, J., Livet, M., Anquetin, S., Lang, M., Neppel, L., Obled, C., Parent-du Chatelet, E., Saulnier, G. M., Walpersdorf, A., and 
Wobrock, W.: The catastrophic flash-flood event of 8-9 September 2002 in the Gard region, France: a first case study for the Cévennes-Vivarais Mediterranean hydrometerorological observatory, J. Hydrometeorol., 6, 34-52, 2005.

Delrieu, G., Boudevillain, B., Nicol, J., Chapon, B., Kirstetter, P. E., Andrieu, H., and Faure, D.: Bollene-2002 Experiment: Radar Quantitative Precipitation Estimation in the Cevennes-Vivarais Region, France, J. Appl. Meteorol. Clim., 48, 1422-1447, 2009.

Delrieu, G., Boudevillain, B., Wijbrans, A., Faure, D., Bonnifait, L., Kirstetter, P.-E., and Confoland, A.: Prototype de ré-analyses pluviométriques pour la région Cévennes-Vivarais, La Météorologie, 83, 35-41, 2013 (in French).

Delrieu, G., Bonnifait, L., Kirstetter, P.-E., and Boudevillain, B.: Dependence of radar quantitative precipitation estimation error on the rain intensity in the Cévennes region, France, Hydrolog. Sci. J., 59, 1-12, 2014a.

Delrieu, G., Wijbrans, A., Boudevillain, B., Faure, D., Bonnifait, L., and Kirstetter, P.-E.: Geostatistical radar-raingauge merging: a novel method for the quantification of rainfall estimation error, Adv. Water Resour., 71, 110-124, 2014b.

Douvinet, J. and Delahaye, D.: Specificities and risk due to "flash floods" in the north of France (Parisian Basin), Geomorphologie - Relief Processus Environnement, 1, 73-90, 2010.

Douvinet, J., Delahaye, D., and Langlois, P.: Measuring surface flow concentrations using a cellular automaton metric: a new way of detecting the potential impacts of flash floods in sedimentary context, Geomorphologie, 1, 27-46, 2013.

Dramais, G., Le Coz, J., Le Boursicaud, R., and Hauet, A.: Jaugeage par radar mobile, protocole et résultats, in: SHF congress: "Hydrométrie 2013”, Paris, 15-16 May 2013, 9 pp., SHF, 2013.

Drobinski, P., Ducrocq, V., Alpert, P., Anagnostou, E., Béranger, K., Borga, M., Braud, I., Chanzy, A., Davolio, S., Delrieu, G., Estournel, C., Filali Boubrahmi, N., Font, J., Grubisic, V., Gualdi, S., Homar, V., Ivancan-Picek, B., Kottmeier, C., Kotroni, V., Lagouvardos, K., Lionello, P., Llasat, M., Ludwig, W., Lutoff, C., Mariotti, A., Richard, E., Romero, R., Rotunno, R., Roussot, O., Ruin, I., Somot, S., Taupier-Letage, I., Tintore, J., Uijlenhoet, R., and Wernli, H.: HyMeX, a 10-year multidisciplinary program on the Mediterranean water cycle, B. Am. Meteorol. Soc., 95, 1063-1082, doi:10.1175/BAMS-D-12-00242.1, 2014.

Ducrocq, V., Braud, I., Davolio, S., Ferretti, R., Flamant, C., Jansa, A., Kalthoff, N., Richard, E., Taupier-Letage, I., Ayral, P.-A., Belamari, S., Berne, A., Borga, M., Boudevillain, B., Bock, O., Boichard, J.-L., Bouin, M.-N., Bousquet, O., Bouvier, C., Chiggiato, J., Cimini, D., Corsmeier, U., Coppola, L., Cocquerez, P., Defer, E., Delanoë, J., Di Girolamo, P., Doerenbecher, A., Drobinski, P., Dufournet, Y., Fourrié, N., Gourley, J., Labatut, L., Lambert, D., Le Coz, J., Marzano, F., Molinié, G., Montani, A., Nord, G., Nuret, M., Ramage, K., Rison, B., Roussot, O., Said, F., Schwarzenboeck, A., Testor, P., Van-Baelen, J., Vincendon, B., Aran, M., and Tamayo, J.: HyMeX-SOP1, the field campaign dedicated to heavy precipitation and flash-flooding in the northwestern Mediterranean, B. Am. Meteorol. Soc., 95, 1083-1100, doi:10.1175/BAMS-D-12-00244.1, 2014.

Fenicia, F., Savenije, H. H. G., Matgen, P., and Pfister, L.: Understanding catchment behavior through stepwise model concept improvement, Water Resour. Res., 44, W01402, doi:10.1029/2006WR005563, 2008.
Fenicia, F., Kavetski, D., and Savenije, H. H. G.: Elements of a flexible approach for conceptual hydrological modeling: 1. Motivation and theoretical development, Water Resour. Res., 47, W11510 doi:10.1029/2010WR010174, 2011.

Fies, J., De Louvigny, N., and Chanzy, A.: The role of stones in soil water retention, Eur. J. Soil Sci., 53, 95-104, 2002.

Filleron, J.-C.: Essais de géographie systématique: les paysages du Nord-Ouest de la Côte d'Ivoire., Thèse de doctorat d'etat, Université de Toulouse - Le Mirail, 2 volumes, 1547 pp. + annexes, 1995 (in French).

Fiori, A., Romanelli, M., Cavalli, D., and Russo, D.: Numerical experiments of streamflow generation in steep catchments, J. Hydrol., 339, 183-192, 2007.

Flügel, W.-A.: Delineating Hydrological Response Units by Geographical Information System analyses for regional hydrological modelling using PRMS/MMS in the drainage basin of the river Bröl in Germany, Hydrol. Process., 9, 423-436, 1995.

Forriez, M., Martin, P., and Nottale, L.: Comparaison entre la classification de Horton et la classification ascendante hiérarchique des confluences. Application au bassin amont des Gardons, Presses universitaires de Rennes, Rennes, 55-67, 2011 (in French).

Furusho, C., Andrieu, H., and Chancibault, K.: Analysis of the hydrological behaviour of an urbanizing basin, Hydrol. Process., 28, 1809-1819, 2014.

Gaume, E. and Borga, M.: Post-flood field inverstigations in upland catchments after major flash floods: proposal of a methodology and illustrations, Journal of Flood Risk Management, 1, 175189, 2008.

Gaume, E., Livet, M., Desbordes, M., and Villeneuve, J. P.: Hydrological analysis of the river Aude, France, flash flood on 12 and 13 November 1999, J. Hydrol., 286, 135-154, 2004.

Gaume, E., Bain, V., Bernardara, P., Newinger, O., Barbuc, M., Bateman, A., Blaskovicová, L., Blöschl, G., Borga, M., Dumitrescu, A., Daliakopoulos, I., Garcia, J., Irimescu, A., Kohnova, S., Koutroulis, A., Marchi, L., Matreata, S., Medina, V., Preciso, E., Sempere-Torres, D., Stancalie, G., Szolgay, J., Tsanis, I., Velasco, D., and Viglione, A.: A compilation of data on European flash floods, J. Hydrol., 367, 70-78, doi:10.1016/j.jhydrol.2008.12.028, 2009.

Godart, A., Anquetin, S., Leblois, E., and Creutin, J.-D.: Contribution of rainfall associated with shallow banded orographic convection to the rainfall climatology of a Mediterranean region, J. Appl. Meteorol. Clim., 50, 2235-2246, 2011.

Gonzalez-Sosa, E., Braud, I., Dehotin, J., Lassabatère, L., AnguloJaramillo, R., Lagouy, M., Branger, F., Jacqueminet, C., Kermadi, S., and Michel, K.: Impact of land use on the hydraulic properties of the topsoil in a small French catchment, Hydrol. Process., 24, 2382-2399, 2010.

Graham, C. B. and McDonnell, J. J.: Hillslope threshold response to rainfall: (2) Development and use of a macroscale model, J. Hydrol., 393, 77-93, 2010.

Graham, C. B., Woods, R. A., and McDonnell, J. J.: Hillslope threshold response to rainfall: (1) A field based forensic approach, J. Hydrol., 393, 65-76, 2010.

Grangeon, T.: Etude multi-échelle de la granulométrie des particules fines générées par érosion hydrique: apports pour la modélisation, Ph.D. thesis, Université de Grenoble, France, 2012 (in French). 
Grayson, R., Moore, I., and McMahon, T.: Physically based hydrologic modelling: 2. Is the concept realistic, Water Resour. Res., 28, 2659-2666, 1992.

Gupta, H. V., Wagener, T., and Liu, Y.: Reconciling theory with observations: elements of a diagnostic approach to model evaluation, Hydrol. Process., 22, 3802-3813, 2008.

Habets, F., Boone, A., Champeaux, J., Etchevers, P., Franchistéguy, L., Leblois, E., Ledoux, E., Le Moigne, P., Martin, E., Morel, S., Noilhan, J., Quintana-Segui, P., Rousset-Regimbeau, F., and Viennot, P.: The SAFRAN-ISBA-MODCOU hydrometerological model applied over France, J. Geophys. Res., 113, D06113, doi:10.1029/2007JD008548, 2008.

Hébrard, O., Voltz, M., Andrieux, P., and Moussa, R.: Spatiotemporal distribution of soil surface moisture in a heterogeneously farmed Mediterranean catchment, J. Hydrol., 329, 110121, 2006.

Herbst, M., Diekkrüger, B., and Vanderborght, J.: Numerical experiments on the sensitivity of runoff generation to the spatial variation of soil hydraulic properties, J. Hydrol., 326, 43-58, 2006.

Hope, D., Billett, M., and Cresser, M.: Export of organic carbon in two river systems in NE Scotland, J. Hydrol., 193, 61-82, 1997.

Hopp, L. and McDonnell, J. J.: Connectivity at the hillslope scale: Identifying interactions between storm size, bedrock permeability, slope angle and soil depth, J. Hydrol., 376, 378-391, 2009.

Hrachowitz, M., Savenije, H. H. G., Blöschl, G., McDonnell, J. J., Sivapalan, M., Pomeroy, J. W., Arheimer, B., Blume, T., Clark, M. P., Ehret, U., Fenicia, F., Freer, J. E., Gelfan, A., Gupta, H. V., Hughes, D. A., Hut, R. W., Montanari, A., Pande, S., Tetzlaff, D., Troch, P. A., Uhlenbrook, S., Wagener, T., Winsemius, H. C., Woods, R. A., Zehe, E., and Cudennec, C.: A decade of Predictions in Ungauged Basins (PUB) - a review, Hydrolog. Sci. J., $58,1-58,2013$.

Huza, J., Teuling, A. J., Braud, I., Grazioli, J., Melsen, L. A., Nord, G., Raupach, T. H., and Uijlenhoet, R.: Precipitation, soil moisture and runoff variability in a small river catchment (Ardèche, France) during HyMeX Special Observation Period 1, J. Hydrol., 516, 330-342, doi:10.1016/j.jhydrol.2014.01.041, 2014.

Iwagami, S., Tsujimura, M., Onda, Y., Shimada, J., and Tanaka, T.: Role of bedrock groundwater in the rainfall-runoff process in a small headwater catchment underlain by volcanic rock, Hydrol. Process., 24, 2771-2783, 2010.

Jachner, S., van den Boogaart, K., and Petzoldt, T.: Statistical methods for the qualitative assessment of dynamic models with time delay (R package qual V), J. Stat. Softw., 22, 1-30, 2007.

James, A. L., McDonnell, J. J., Tromp-van Meerveld, I., and Peters, N. E.: Gypsies in the palace: experimentalist's view on the use of 3 -D physics-based simulation of hillslope hydrological response, Hydrol. Process., 24, 3878-3893, 2010.

Joerin, C., Beven, K., Musy, A., and Talamba, D.: Study of hydrological processes by the combination of environmental tracing and hill slope measurements: application on the Haute-Mentue catchment, Hydrol. Process., 19, 3127-3145, 2005.

Kientzler, P. and Naef, F.: Subsurface storm flow formation at different hillslopes and implications for the "old water paradox", Hydrol. Process., 22, 104-116, 2008.

Kirchner, J.: Getting the right answer for the right reasons: linking measurements, analyses, and models to advance the science of hydrology, Water Resour. Res., 42, W03S04, doi:10.1029/2005WR004362, 2006.
Kirchner, J. W.: Catchments as simple dynamical systems: Catchment characterization, rainfall-runoff modeling, and doing hydrology backward, Water Resour. Res., 45, W02429, doi:10.1029/2008WR006912, 2009.

Kirstetter, P. E., Delrieu, G., Boudevillain, B., and Obled, C.: Toward an error model for radar quantitative precipitation estimation in the Cevennes-Vivarais region, France, J. Hydrol., 394, 28 $41,2010$.

Klemes, V.: Dilettantism in hydrology: transition of destiny?, Water Resour. Res., 22, 177-188, 1986.

Kralisch, S., Krause, P., Fink, M., Fischer, C., and Flügel, W.: Component based environmental modelling using the JAMS framework, in: MODSIM 2007 International Congress on Modelling and Simulation, edited by: Oxley, L. and Kulasiri, D., Modelling and Simulation Society of Australia and New Zealand, 812-818, 2007.

Krause, P., Bäse, F., Bende-Michl, U., Fink, M., Flügel, W., and Pfenning, B.: Multiscale investigations in a mesoscale catchment - hydrological modelling in the Gera catchment, Adv. Geosci., 9, 53-61, doi:10.5194/adgeo-9-53-2006, 2006.

Laio, F. and Tamea, S.: Verification tools for probabilistic forecasts of continuous hydrological variables, Hydrol. Earth Syst. Sci., 11, 1267-1277, doi:10.5194/hess-11-1267-2007, 2007.

Land, M., Ingri, J., Andersson, P. S., and Ö-hlander, B.: Ba/Sr, $\mathrm{Ca} / \mathrm{Sr}$ and ${ }^{87} \mathrm{Sr} /{ }^{86} \mathrm{Sr}$ ratios in soil water and groundwater: implications for relative contributions to stream water discharge, Appl. Geochem., 15, 311-325, 2000.

Lassabatère, L., Angulo-Jaramillo, R., Soria-Ugalde, J., Cuenca, R., Braud, I., and Haverkamp, R.: Beerkan estimation of soil transfer parameters through infiltration experiments, Soil Sci. Soc. Am. J., 70, 521-532, 2006.

Latron, J. and Gallart, F.: Seasonal dynamics of runoff-contributing areas in a small mediterranean research catchment (Vallcebre, Eastern Pyrenees), J. Hydrol., 335, 194-206, 2007.

Latron, J., Soler, M., LLorens, P., and Gallart, F.: Spatial and temporal variability of the hydrological response in a small Mediterranean research catchment (Vallcebre, Eastern Pyrenees), Hydrol. Process., 22, 775-787, 2008.

Lebel, T., Cappelaere, B., Galle, S., Hanan, N., Kergoat, L., Levis, S., Vieux, B., Descroix, L., Gosset, M., Mougin, E., Peugeot, C., and Seguis, L.: AMMA-CATCH studies in the Sahelian region of West-Africa: An overview, J. Hydrol., 375, 3-13, 2009.

Leblois, E. and Creutin, J.-D.: Space-time simulation of intermittent rainfall with prescribed advection field: Adaptation of the turning band method, Water Resour. Res., 49, 3375-3387, 2013.

Le Bourgeois, O., Bouvier, C., and Ayral, P.-A.: Caractérisation des propriétés hydrodynamiques d'un sol cévenol par modélisation inverse des humidités des sols, in: 37èmes Journées Scientifiques du GFHN, Paris, France, 135-144, 2012 (in French).

Le Boursicaud, R., Pénard, L., Hauet, A., and Le Coz, J.: Gauging extreme floods on YouTube: Application of LSPIV to home movies for the post-event determination of stream discharges, Hydrol. Process., submitted, 2014.

Lecompte, M.: Analyse des rapports climat - végétation par une méthode d'échantillonnage continu, Bulletin de la Société des Sciences Naturelles et Physiques du Maroc, 53, 37-61, 1973 (in French).

Le Coz, J., Hauet, A., Pierrefeu, G., Dramais, G., and Camenen, B.: Performance of image-based velocimetry (LSPIV) applied to 
flash-flood discharge measurements in Mediterranean rivers, J. Hydrol., 394, 42-52, 2010.

Le Coz, J., Camenen, B., Peyrard, X., and Dramais, G.: Uncertainty in open-channel discharge measured with the velocity-area method, Flow Meas. Instrum., 26, 18-29, 2012.

Le Coz, J., Renard, B., Bonnifait, L., Branger, F., and Le Boursicaud, R.: Combining hydraulic knowledge and uncertain gaugings in the estimation of hydrometric rating curves: a Bayesian approach, J. Hydrol., 509, 573-587, 2014.

Lehmann, P., Hinz, C., McGrath, G., Tromp-van Meerveld, H. J., and McDonnell, J. J.: Rainfall threshold for hillslope outflow: an emergent property of flow pathway connectivity, Hydrol. Earth Syst. Sci., 11, 1047-1063, doi:10.5194/hess-11-10472007, 2007.

Le Lay, M. and Saulnier, G. M.: Exploring the signature of climate and lanscape spatial variabilities in flash flood events: case of the 8-9 September 2002 Cévennes-Vivarais catastrophic event, Geophys. Res. Lett., 34, L13401, doi:10.1029/2006WR005257, 2007.

Lepioufle, J.-M., Leblois, E., and Creutin, J.-D.: Variography of rainfall accumulation in presence of advection, J. Hydrol., 464, 494-504, 2012.

Lexartza-Artza, I. and Wainwright, J.: Hydrological connectivity: Linking concepts with practical implications, Catena, 79, 146$152,2009$.

Lin, H.: Linking principles of soil formation and flow regimes, J. Hydrol., 393, 3-19, 2010.

Lin, H., Bouma, J., Pachepsky, Y., Western, A. W., Thompson, J., van Genuchten, M. T., Vogel, H. J., and Lilly, A.: Hydropedology: synergetic integration of pedology and hydrology, Water Resour. Res., 42, W05301, doi:10.1029/2005WR004085, 2006 a.

Lin, H. S., Kogelmann, W., Walker, C., and Bruns, M. A.: Soil moisture patterns in a forested catchment: A hydropedological perspective, Geoderma, 131, 345-368, $2006 \mathrm{~b}$.

Loew, A. and Mauser, W.: Inverse modeling of soil characteristics from surface soil moisture observations: potential and limitations, Hydrol. Earth Syst. Sci. Discuss., 5, 95-145, doi:10.5194/hessd-5-95-2008, 2008.

Maes, S., Megank, S., and Leray, P.: An integral approach to causal infeinfer with latent variables, London College Publications, England, 17-41, 2007.

Malam, A.: Etats de surface et fonctionnement hydrodynamique multi-échelles des bassins sahéliens; études expérimentales en zones cristalline et sédimentaire, Ph.D. thesis, Université Joseph Fourier, Grenoble, 2014 (in French).

Marchi, L., Borga, M., Preciso, E., Sangati, M., Gaume, E., Bain, V., Delrieu, G., Bonnifait, L., and Pogacnik, N.: Comprehensive post-event survey of a flash flood in Western Slovenia: observation strategy and lessons learned, Hydrol. Process., 23, 37613770, 2009.

Marchi, L., Borga, M., Preciso, E., and Gaume, E.: Characterisation of selected extreme flash floods in Europe and implications for flood risk management, J. Hydrol., 394, 118-133, 2010.

Maréchal, D.: Du drain potentiel au drain réel: utilisation de l'imagerie satellite à Très Haute Résolution et de l'observation hydrologique pour la détermination et la caractérisation des chemins de l'eau à différentes échelles sur les bassin versant soumis aux crues éclair, Ph.D. thesis, Ecole Nationale Supérieure des Mines de St-Etienne, 2011 (in French).
Maréchal, D., Ayral, P.-A., Bailly, J.-S., Puech, C., and Sauvagnargues-Lesage, S.: Sur l'origine morphologique des écoulements par l'analyse d'observations hydrologiques distribuées. Application à deux bassins versants cévenols (Gard, France), Géomorphologie: relief, processus, environnement, 1, 47-62, 2012 (in French)

Martin, P.: Les inondations du 15 juin 2010 dans le Centre Var: réflexion sur un épisode exceptionnel, Etudes de Géographie Physique, XXXVII, 41-76, 2010 (in French).

Martin, P., Nottale, L., and Ayral, P.-A.: Modélisation fractale de courbes de niveau à partir de deux modèles nnumérique de terrain (MNT 50 m et MNT Lidar 0.5 m), Cybergeo, submitted, 2014 (in French).

Matheron, G.: The intrinsic random functions and their applications, Adv. Appl. Probab., 5, 439-468, 1973.

McDonnell, J., Sivapalan, M., Vaché, K., Dunn, S., Grant, G., Haggerty, R., Hinz, C., Hooper, R., Kirchner, J., Roderick, M., Selker, J., and Weiler, M.: Moving beyond heterogeneity and process complexity: a new vision for watershed hydrology, Water Resour. Res., 43, W07301, doi:10.1029/2006WR005467, 2007.

McDonnell, J. J., McGuire, K., Aggarwal, P., Beven, K. J., Biondi, D., Destouni, G., Dunn, S., James, A., Kirchner, J., Kraft, P., Lyon, S., Maloszewski, P., Newman, B., Pfister, L., Rinaldo, A., Rodhe, A., Sayama, T., Seibert, J., Solomon, K., Soulsby, C., Stewart, M., Tetzlaff, D., Tobin, C., Troch, P., Weiler, M., Western, A., Wörman, A., and Wrede, S.: How old is streamwater? Open questions in catchment transit time conceptualization, modelling and analysis, Hydrol. Process., 24, 1745-1754, 2010.

Molinié, G., Ceresetti, D., Anquetin, S., Creutin, J. D., and Boudevillain, B.: Rainfall regime of a mountainous Mediterranean region: statistical analyses at short time steps, J. Appl. Meteorol. Clim., 51, 429-448, 2012.

Morin, E., Goodrich, D. C., Maddox, R. A., Gao, X., Gupta, H. V., and Sorooshian, S.: Spatial patterns in thunderstorm rainfall events and their coupling with watershed hydrological response, Adv. Water Resour., 29, 843-860, doi:10.1016/j.advwatres.2005.07.014, 2006.

Morschel, J.: L'eau et les paysages dans la Dorsale Tunisienne: expliquer le cheminement des flux hydriques en fonction des organisations présentes dans le milieu naturel, Ph.D. thesis, Université de Nice-Sophia-Antipolis, France, 2006 (in French).

Morschel, J.: Les segments de paysage, un approche différente permettant la compréhension et la discrétisation du milieu naturel, Etudes de Géographie Physique, XXXVIII, 3-22, 2011 (in French).

Moussa, R.: When monstrosity can be beautiful while normality can be ugly: assessing the performance of event-based flood models, Hydrol. Sci. J., 55, 1074-1084, 2010.

Moussa, R., Chahinian, N., and Bocquillon, C.: Distributed hydrological modelling of a Mediterranean mountainous catchment Model construction and multi-site validation, J. Hydrol., 337, 35-51, 2007.

Nicolas, M.: Etude expérimentale et numérique du ruissellement de surface: effets des variations d'intensité de la pluie, application à une parcelle de vigne en Cévennes-Vivarais, Ph.D. thesis, Université de Grenoble, France, 2010 (in French).

Norbiato, D., Borga, M., Merz, R., Blöschl, G., and Carton, A.: Controls on event runoff coefficients in the eastern Italian Alps, J. Hydrol., 375, 312-325, 2009. 
Ollagnier, M.: Climatologie des pluies en égion Cévennes-Vivarais: caractérisation des situations pluvieuses à l'échelle régionale, M.S. thesis, Université de Grenoble, France, M2R "Science de la Terre - Eau, Climat, Environnement”, 2013 (in French).

Pellarin, T., Delrieu, G., Saulnier, G. M., Andrieu, H., Vignal, B., and Creutin, J. D.: Hydrologic visibility of weather radar systems operating in mountainous regions: Case study for the Ardèche Catchment (France), J. Hydrometeorol., 3, 539-555, 2002.

Rawls, W. and Brakensiek, D.: Prediction of soil water properties for hydrologic modeling, in: Watershed Management in the eighties, edited by: Jones, E. and Ward, T., ASCE, Denver, Colorado, 293-299, 1985.

Reed, P., Brooks, R., Davis, K., DeWalle, D., Dressler, K., Duffy, C., Lin, H., Miller, D., Najjar, R., Salvage, K., Wagener, T., and Yarnal, B.: Bridging river basin scales and processes to assess human-climae impacts and the terrestrial hydrologic system, Water Resour. Res., 42, W07418, doi:10.1029/2005WR004153, 2006.

Reggiani, P., Sivapalan, M., and Hassanizadeh, S.: A unifying framework for watershed thermodynamics: balance equations for mass, momentum, energy and entropy, and the second law of thermodynamics, Adv. Water Resour., 22, 367-598, 1998.

Renard, B., Kavetski, D., Leblois, E., Thyer, M., Kuczera, G., and Franks, S.: Towards a reliable decomposition of predictive uncertainty in hydrological modeling: characterizing rainfall errors using conditional simulation, Water Resour. Res., 47, W11516, doi:10.1029/2011WR010643, 2011.

Rogger, M., Pirkl, H., Viglione, A., Komma, J., Kohl, B., Kirnbauer, R., Merz, R., and Blöschl, G.: Step changes in the flood frequency curve: Process controls, Water Resour. Res., 48, W05544, doi:10.1029/2011wr011187, 2012.

Ross, P.: Modeling soil water and solute transport - Fast, simplified numerical solutions, Agron. J., 95, 1352-1361, 2003.

Ruin, I., Creutin, J., Anquetin, S., and Lutoff, C.: Human exposure to flash-floods-relation between flood parameters and human vulnerability during a storm of September 2002 in Southern France, J. Hydrol., 361, 199-213, 2008.

Samaniego, L., Kumar, R., and Attinger, S.: Multiscale parameter regionalization of a grid-based hydrologic model at the mesoscale, Water Resour. Res., 46, W05523, doi:10.1029/2008WR007327, 2010.

Sangati, M., Borga, M., Rabuffeti, D., and Bechini, R.: Influence of rainfall and soil properties spatial aggregation on extreme flash flood response modelling: an evaluation based on the Sesia river basin, North Western Italy, Adv. Water Resour., 32, 1090-1106, 2009.

Sarrazin, B.: MNT et observations multi-locales du réseau hydrographique d'un petit bassin versant rural dans une perspective d'aide à la modélisation hydrologique spatialisée, Ph.D. thesis, Université de Grenoble, France, 2012 (in French).

Saulnier, G. M. and Le Lay, M.: Sensitivity of flash-flood simulations on the volume, the intensity, and the localization of rainfall in the Cévennes-Vivarais region (France), Water Resour. Res., 45, W10425, doi:10.1029/2008WR006906, 2009.

Schmocker-Fackel, P., Naef, F., and Scherrer, S.: Identifying runoff processes on the plot and catchment scale, Hydrol. Earth Syst. Sci., 11, 891-906, doi:10.5194/hess-11-891-2007, 2007.
Schwartz, R. C., Evett, S. R., and Unger, P. W.: Soil hydraulic properties of cropland compared with reestablished and native grassland, Geoderma, 116, 47-60, 2003.

Sivapalan, M.: Prediction in ungauged basins: a grand challenge for theoretical hydrology, Hydrol. Process., 17, 3163-3170, 2003 a.

Sivapalan, M.: Process complexity at hillslope scale, process simplicity at the watershed scale: is there a connection?, Hydrol. Process., 17, 1037-1041, 2003b.

Sivapalan, M.: The secret to "doing better hydrological science": change the question!, Hydrol. Process., 23, 1391-1396, 2009.

Tramblay, Y., Bouvier, C., Martin, C., Didon-Lescot, J.-F., Todorovik, D., and Domergue, J.-M.: Assessment of initial soil moisture conditions for event-based rainfall-runoff modelling, J. Hydrol., 387, 176-187, 2010.

Troch, P., Paniconi, C., and van Loon, E.: Hillslope-storage Boussinesq model for subsurface flow and variable source areas along complex hillslopes: 1. Formulation and characteristic response, Water Resour. Res., 39, 1316, doi:10.1029/2002WR001728, 2003.

Troch, P. A., Berne, A., Bogaart, P., Harman, C., Hilberts, A. G. J., Lyon, S. W., Paniconi, C., Pauwels, V. R. N., Rupp, D. E., Selker, J. S., Teuling, A. J., Uijlenhoet, R., and Verhoest, N. E. C.: The importance of hydraulic groundwater theory in catchment hydrology: The legacy of Wilfried Brutsaert and Jean-Yves Parlange, Water Resour. Res., 49, 5099-5116, 2013.

Tromp-van Meerveld, H. J. and McDonnell, J. J.: Threshold relations in subsurface stormflow: 2. The fill and spill hypothesis, Water Resour. Res., 42, W02411, doi:10.1029/2004WR003800, 2006.

Tromp-van Meerveld, H. J., Peters, N. E., and McDonnell, J. J.: Effect of bedrock permeability on subsurface stormflow and the water balance of a trenched hillslope at the Panola Mountain Research Watershed, Georgia, USA, Hydrol. Process., 21, 750-769, 2007.

Troutman, B. M. and Karlinger, M. R.: Regional flood probabilities, Water Resour. Res., 39, 1095, doi:10.1029/2001WR001140, 2003.

Uchida, T., Tromp-van Meerveld, I., and McDonnell, J. J.: The role of lateral pipe flow in hillslope runoff response: an intercomparison of non-linear hillslope response, J. Hydrol., 311, 117-133, 2005.

Vandervaere, J., Vauclin, M., and Elrick, D.: Transient flow from tension infiltrometers: II. Four methods to determine sorptivity and conductivity, Soil Sci. Soc. Am. J., 64, 1271-1284, 2000.

Vandervaere, J., Ugarte Nano, C., and Prat, C.: The use of ponding time to determine soil hydraulic properties during infiltration prior to runoff, Hydrol. Earth Syst. Sci., in preparation, 2014.

Vannier, O.: Apport de la odélisation hydrologique distribuée régionale dans la compréhension des processus hydrologiques en zone méditerranéenne, Ph.D. thesis, Institut National Polytechnique de Grenoble, France, 2013 (in French).

Vannier, O., Braud, I., and Anquetin, S.: ReRegion estimation of catchment-scale soil properties by means of streamflow recession analysis for use in distributed hydrological models, Hydrol. Process., doi:10.1002/hyp.10101, online first, 2013.

Varado, N., Braud, I., Galle, S., Le Lay, M., Séguis, L., Kamagate, B., and Depraetere, C.: Multi-criteria assessment of the Representative Elementary Watershed approach on the Donga catchment (Benin) using a downward approach of model complexity, 
Hydrol. Earth Syst. Sci., 10, 427-442,doi:10.5194/hess-10-4272006, 2006a.

Varado, N., Ross, P., Braud, I., and Haverkamp, R.: Assessment of an efficient numerical solution of the Richards' equation for bare soil, J. Hydrol., 323, 244-257, 2006 b.

Vázquez, R. F., Willems, P., and Feyen, J.: Improving the predictions of a MIKE SHE catchment-scale application by using a multi-criteria approach, Hydrol. Process., 22, 2159-2179, 2008.

Viallet, P., Debionne, S., Braud, I., Dehotin, J., Haverkamp, R., Saadi, Z., Anquetin, S., Branger, F., and Varado, N.: Towards multi-scale integrated hydrological models using the LIQUID framework, in: 7th International Conference on Hydroinformatics, edited by: Gourbesville, P., Cunge, J., Guinot, V., and Liong, S., Nice, France, 1, 542-549, 2006.

Viglione, A., Chirico, G. B., Komma, J., Woods, R., Borga, M., and Blöschl, G.: Quantifying space-time dynamics of flood event types, J. Hydrol., 394, 213-229, 2010a.

Viglione, A., Chirico, G. B., Woods, R., and Blöschl, G.: Generalised synthesis of space-time variability in flood response: An analytical framework, J. Hydrol., 394, 198-212, 2010 b.

Weiler, M. and McDonnell, J.: Virtual experiments: a new approach for improving process conceptualization in hillslope hydrology, J. Hydrol., 285, 3-18, 2004.
Weiler, M. and McDonnell, J. J.: Conceptualizing lateral preferential flow and flow networks and simulating the effects on gauged and ungauged hillslopes, Water Resour. Res., 43, W03403, doi:10.1029/2006WR004867, 2007.

Willems, P.: A time series tool to support the multi-criteria performance evaluation of rainfall-runoff models, Environ. Modell. Softw., 24, 311-321, 2009.

Wollschläger, U., Pfaff, T., and Roth, K.: Field-scale apparent hydraulic parameterisation obtained from TDR time series and inverse modelling, Hydrol. Earth Syst. Sci., 13, 1953-1966, doi:10.5194/hess-13-1953-2009, 2009.

Wood, E., Sivapalan, M., Beven, K., and Band, L.: Effect of spatial variability and scale with implication to hydrologic modeling, J. Hydrol., 102, 29-47, 1988.

Zanon, F., Borga, M., Zoccatelli, D., Marchi, L., Gaume, E., Bonnifait, L., and Delrieu, G.: Hydrological analysis of a flash flood across a climatic and geologic gradient The September 18, 2007 event in Western Slovenia, J. Hydrol., 394, 182-197, 2010.

Zehe, E., Lee, H., and Sivapalan, M.: Dynamical process upscaling for deriving catchment scale state variables and constitutive relations for meso-scale process models, Hydrol. Earth Syst. Sci., 10, 981-996, doi:10.5194/hess-10-981-2006, 2006. 